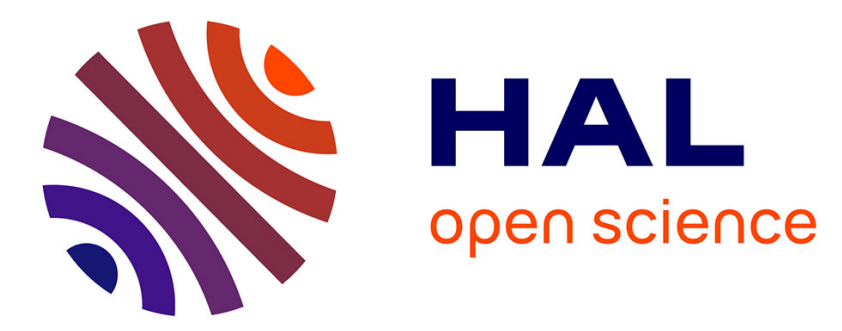

\title{
Intergenerational effects on mouse sperm quality after in utero exposure to acetaminophen and ibuprofen
}

Moïra Rossitto, Candice Marchive, Alain Pruvost, Eli Sellem, Aurelie Ghettas, Stéphanie Badiou, Thibault Sutra, Francis Poulat, Pascal Philibert, Brigitte Boizet-Bonhoure

\section{To cite this version:}

Moïra Rossitto, Candice Marchive, Alain Pruvost, Eli Sellem, Aurelie Ghettas, et al.. Intergenerational effects on mouse sperm quality after in utero exposure to acetaminophen and ibuprofen. FASEB Journal, 2019, 33 (1), pp.339-357. 10.1096/fj.201800488RRR . hal-01832367

\section{HAL Id: hal-01832367 \\ https://hal.umontpellier.fr/hal-01832367}

Submitted on 22 Jun 2020

HAL is a multi-disciplinary open access archive for the deposit and dissemination of scientific research documents, whether they are published or not. The documents may come from teaching and research institutions in France or abroad, or from public or private research centers.
L'archive ouverte pluridisciplinaire HAL, est destinée au dépôt et à la diffusion de documents scientifiques de niveau recherche, publiés ou non, émanant des établissements d'enseignement et de recherche français ou étrangers, des laboratoires publics ou privés. 


\title{
Intergenerational effects on mouse sperm quality after in utero exposure to acetaminophen and ibuprofen
}

\author{
Moïra Rossitto, ${ }^{*}$ Candice Marchive, ${ }^{*}$ Alain Pruvost, ${ }^{\dagger}$ Eli Sellem, ${ }^{\ddagger}$ Aurélie Ghettas, ${ }^{\dagger}$ Stéphanie Badiou, ${ }^{\$}$ \\ Thibault Sutra, ${ }^{\S}$ Francis Poulat, ${ }^{*}$ Pascal Philibert, ${ }^{*}, \S$ and Brigitte Boizet-Bonhoure ${ }^{*, 1}$ \\ *Institute of Human Genetics, Centre National de la Recherche Scientifique (CNRS), University of Montpellier, Montpellier, France; ${ }^{\dagger}$ Service de \\ Pharmacologie et d'Immunoanalyse (SPI), Small Molecules Analysis by Mass Spectrometry (SMArt-MS), Commissariat à l'Energie Atomique \\ (CEA), Institut National de la Recherche Agronomique (INRA), Université Paris-Saclay, Gif sur Yvette, France; ${ }^{*}$ Research and Development \\ Department, Allice, Biology of Reproduction, INRA Domaine de Vilvert, Jouy en Josas, France; and ${ }^{\S}$ Département de Biochimie et d'Hormonologie, \\ Hopital Lapeyronie, Centre Hospitalier Universitaire (CHU) de Montpellier; PhyMedExp, INSERM Unité 1046, CNRS Unité Mixte de Recherche \\ (UMR) 9214, Université de Montpellier, Montpellier, France
}

\begin{abstract}
Nonsteroidal antiinflammatory drugs and analgesic drugs, such as $N$-acetyl-p-aminophenol (APAP; acetaminophen, paracetamol), are widely used by pregnant women. Accumulating evidence has indicated that these molecules can favor genital malformations in newborn boys and reproductive disorders in adults. However, the consequences on postnatal testis development and adult reproductive health after exposure during early embryogenesis are still unknown. Using the mouse model, we show that in utero exposure to therapeutic doses of the widely used APAP-ibuprofen combination during the sex determination period leads to early differentiation and decreased proliferation of male embryonic germ cells, and early 5-methylcytosine and extracellular matrix protein deposition in $13.5 \mathrm{~d}$ postcoitum exposed testes. Consequently, in postnatal testes, Sertoli-cell maturation is delayed, the Leydigcell compartment is hyperplasic, and the spermatogonia A pool is decreased. This results in a reduced production of testosterone and in epididymal sperm parameter defects. We observed a reduced sperm count (19\%) in uteroexposed (F0) adult males and also a reduced sperm motility (40\%) in their offspring (F1) when both parents were exposed, which leads to subfertility among the 6 mo old F1 animals. Our study suggests that the use of these drugs during the critical period of sex determination affects the germ-line development and leads to adverse effects that could be passed to the offspring.--Rossitto, M., Marchive, C., Pruvost, A., Sellem, E., Ghettas, A., Badiou, S., Sutra, T., Poulat, F., Philibert, P., Boizet-Bonhoure, B. Intergenerational effects on mouse sperm quality after in utero exposure to acetaminophen and ibuprofen.
\end{abstract}

KEY WORDS: NSAID $\cdot$ analgesic $\cdot$ germ cell $\cdot$ differentiation $\cdot$ sperm parameters

ABBreviATIONS: ALC, adult Leydig cell; APAP, $N$-acetyl-p-aminophenol (acetaminophen, paracetamol); ASA, acetylsalicylic acid (aspirin); CASA, computer-assisted semen analyses; COX1-3, cyclooxygenase 1-3; Dnmt, de novo DNA methylase; dpc, days postcoitum; dpp, days postpartum; ECM, extracellular matrix; EdU, 5-ethynyl-2'-deoxyuridine; eSpd, elongated spermatid; F0AI, mice exposed in utero to $\mathrm{N}$-acetyl-p-aminophenol + ibuprofen; F0WT, mice not exposed in utero to $\mathrm{N}$-acetyl-p-aminophenol + ibuprofen; F1AI-AI, male F0AI $\times$ female F0AI mice; F1AI-WT, male F0AI $\times$ female FOWT mice; F1WT, male F0WT $\times$ female F0WT mice; F1WT-AI, male FOWT $\times$ female FOAI mice; FACS, fluorescence-activated cell sorting; 5-mC, 5-methylcytosine; GEO, Gene Expression Omnibus; IBU, ibuprofen; LC-MS/MS, liquid chromatography-tandem mass spectrometry; NSAID, nonsteroidal antiinflammatory drug; PAS, periodic acid-Schiff; PG, prostaglandin; PGC, primordial germinal cell; qRT-PCR, quantitative RT-PCR; $\mathrm{rSpd}$, round spermatid; SpgA/B, spermatogonia A/B; Spz, spermatozoa; STR, straightness; TXA2, thromboxane; UPLC, ultraperformance liquid chromatography-tandem mass spectrometry; VAP, average path velocity; VCL, curvilinear velocity; VSL, straight line velocity

${ }^{1}$ Correspondence: Institute of Human Genetics, CNRS, UMR9002, University of Montpellier, 141 rue de la Cardonille, 34396 Montpellier Cedex 5, France. E-mail: brigitte.boizet@igh.cnrs.fr
In humans, genital malformations in newborn boys such as cryptorchidism and hypospadias as well as reproductive disorders in adults have been progressively increasing during the last 3 decades (1). These disorders may comprise a testicular dysgenesis syndrome with a common origin in fetal life and could be favored by exposure to environmental chemicals, such as pesticides, endocrine disruptors, or therapeutic drugs (2). Exposure in utero to endocrine disruptors can also have intergenerational adverse effects, particularly in gonadal germ cells (3), where they could lead to reduced semen quality and fertility (2). The critical window for exposure is the onset of fetal gonadal sex determination. This occurs during the epigenetic reprogramming of male gonocytes (4) that then generate the spermatogonia pool in the postnatal testis to support spermatogenesis throughout the adult reproductive life (5).

Nonsteroidal antiinflammatory drugs (NSAIDs) such as aspirin (ASA) and ibuprofen (IBU), and analgesic drugs such as $N$-acetyl- $p$-aminophenol (APAP; acetaminophen, 
paracetamol) are widely used to treat inflammation and pain (6). APAP and IBU are among the most commonly prescribed drugs in the first trimester of pregnancy (7-9), and both APAP and NSAIDs can cross the placental barrier $(10,11)$. Epidemiologic studies reported that exposure to APAP or NSAIDs during the first and second trimesters of gestation is associated with an increased risk of cryptorchidism (6). Furthermore, in a large population-based mother-child cohort, an association between simultaneous maternal use of both APAP and NSAID and shorter anogenital distance was found, whereas APAP use alone did not affect anogenital distance in the male offspring (12). Experimental in vivo/ex vivo investigations in rodents (13-16) and ex vivo studies using human testicular explants (17-20) showed that nontherapeutic doses of these drugs cause mild or contradictory effects on testosterone secretion. Also, when administered to adult men, IBU disrupts the hypothalamus-pituitary-gonad axis, inducing an increase in LH secretion and a decrease in testosterone production; ex vivo studies using adult testicular explants confirmed the antiandrogenic action of IBU (21).

However, the consequences of APAP and NSAID exposure on the adult reproductive health are still largely unknown (22). A recent study showed the association between APAP and its metabolite $p$-aminophenol (quantified in urine) and reduced sperm quality in 500 male partners of couples planning for pregnancy (23). Moreover, in adult rats, long-term treatment with APAP at high doses impairs sexual competence, sperm count and quality, and fertility (24). Conversely, adult mouse sperm parameters are not affected after in utero exposure to low doses of ASA or IBU (25). Similarly, in vivo administration of APAP or indomethacin to pregnant rats during embryogenesis decreases the number of fetal germ cells and accelerates their embryonic differentiation but does not affect the fertility of adult male rats (26). In females, the number of primordial germ cells is reduced (27) and meiotic entry delayed (26) in fetal mouse and rat ovaries, respectively, leading to a decreased number of follicles in adult mouse ovaries (27) and reduced fertility in F1 and F2 rat females (26). In addition, exposure of ex vivo cultures of human embryonic ovaries to IBU induces a decrease in the germ-cell pool due to a decrease in their proliferation and an increase in their apoptosis (28).

NSAIDs and APAP target the enzymes cyclooxygenases 1-3 (COX1-3). COX1-3 catalyze the conversion of arachidonic acid into prostaglandin (PG) H2, which that is then converted into various PGs $\left(\mathrm{PGE}_{2}, \mathrm{PGD}_{2}, \mathrm{PGI}_{2}\right.$, PGF2 $\alpha$ ) by the action of specific terminal PG synthases (29). Most PGs play multiple roles in embryonic and adult gonads and consequently in various aspects of male and female reproduction (30-32). Moreover, compounds that block the arachidonic acid cascade can inhibit testosterone synthesis and the development of male genitalia (33). Because prostanoid receptors and PG synthases (PGDS, PGES, and PGIS) are widely expressed in $11.5 \mathrm{~d}$ postcoitum (dpc) undifferentiated male gonads (34) and $\mathrm{PGD}_{2}$ signaling is involved in the early steps of testis organogenesis [both somatic $(35,36)$ and germ-line cells (37)], embryonic gonads might be targets of these drugs. Therefore, using human-relevant doses $(19,38)$, we investigated the effect of early in utero exposure (between 10.5 and $13.5 \mathrm{dpc}$ ), the period of gonad sex determination in mice that corresponds to the last part of the first trimester, 6 to $10 \mathrm{wk}$, of gestation in humans to APAP and NSAIDs as single drugs or for the first time in combination. Using the APAP + IBU combination, we found that germ-cell differentiation and maturation were affected in male embryonic and postnatal testes, leading to abnormal epididymal sperm parameters in adult animals directly exposed in utero (F0) and their offspring (F1 generation) when both parents were exposed. These data provide new findings on the negative effects of these pharmaceutical molecules, which are widely used by pregnant women, on gonad development and maturation and consequently on reproductive health.

\section{MATERIALS AND METHODS}

\section{Animals and experimental protocols}

For all experiments, wild-type 10.5 dpc CD1 females were purchased from Janvier Laboratories (Le Genest-Saint-Isle, France). All animal experiments were conducted according to procedures approved by the Réseau des Animaleries de Montpellier (34-366 for B.B.-B.) and by the Regional Ethics Committee. Animals were kept and bred at the Institute of Human Genetics Animal Care Facility in controlled environmental conditions. APAP, ASA, and IBU stock solutions (500, 277, and $219 \mathrm{mM}$, respectively) (MilliporeSigma, Burlington, MA, USA) were prepared in ethanol and 10-fold diluted with PBS before oral administration between 10.5 and $13.5 \mathrm{dpc}$. For experiments with single drugs, $30 \mathrm{mg} / \mathrm{kg}$ APAP, $50 \mathrm{mg} / \mathrm{kg}$ ASA, and $15 \mathrm{mg} / \mathrm{kg} \operatorname{IBU}(19,20,27,39)$ or $9.7 \%$ ethanol (control) were administered daily at 2 times $(150 \mu 1$ by gavage, $6 \mathrm{~h}$ apart) ( $n=6$ experiments with 2 pregnant females for each condition). For experiments with 2 drugs $[30 \mathrm{mg} / \mathrm{kg} / \mathrm{d}$ APAP $+50 \mathrm{mg} / \mathrm{kg} / \mathrm{d}$ ASA, and $30 \mathrm{mg} / \mathrm{kg} / \mathrm{d}$ APAP $+15 \mathrm{mg} / \mathrm{kg} / \mathrm{d}$ IBU or ethanol and APAP $+\operatorname{APAP}(60 \mathrm{mg} / \mathrm{kg} / \mathrm{d})$ as controls], the same doses for each drug were alternately administrated every $3 \mathrm{~h}$ ( 4 times, $150 \mu \mathrm{l}$ by gavage) $(n=4$ experiments with 2 pregnant females for each condition). 5-Ethynyl2'-deoxyuridine (EdU) $(2.5 \mathrm{mM} / 150 \mu \mathrm{l})$ (Thermo Fisher Scientific, Waltham, MA, USA) was intraperitoneally injected in pregnant females $2 \mathrm{~h}$ before they were humanely killed and subsequent embryo dissection, and in $8 \mathrm{~d}$ postpartum (dpp) pups. Treated pregnant females gave birth to the F0 offspring (exposed in utero); then 8 wk old F0 males and 6 wk old F0 females (F0AI) were mated to generate F1 animals. Neither sibling nor cousin animals were crossed to avoid inbreeding artifacts.

\section{Immunofluorescence}

Mesogonads from embryos and from 8, 14, 21, and $30 \mathrm{dpp}$ postnatal testes and 3 mo old adult testes from F0 and F1 animals ( $n=6-10$ animals/condition, each from independent exposed females or mating) were dissected. Fixed testes were embedded in paraffin, and sections were as previously described (35). Spreads were made from sperm suspension in Tris-citricfructose buffer ( $n=3$ for each mating) and fixed with $4 \%$ paraformaldehyde (Sigma-Aldrich). Primary antibodies and dilutions used in immunofluorescence experiments [performed as previously described $(34,35)]$ included the following: rabbitSox9 [1:300, homemade (40)], rabbit-Amh [1:400, a gift from N. diClemente (University of Paris Diderot) (41)], rabbit L-Pgds [1:400 homemade (35)], rabbit Vasa/Mvh (1:300, AB4330; MilliporeSigma), mouse Vasa/Mvh (1:2000, ab27591; Abcam, 
Cambridge, MA, USA), rabbit-Lin28a (1:400, 11724-1-AP; Proteintech, Rosemont, IL, USA), rabbit-5-methylcytosine (5-mC; 1:1500, 28692; Cell Signaling Technology, Danvers, MA, USA), CoupTFII/Nr2f2 (1:300, H7147; R\&D Systems, Minneapolis, MN, USA), mouse- $\alpha$-tubulin and -acetylated $\alpha$-tubulin clone 611-B1 (1:1000, T9026, T6793; MilliporeSigma), and rabbit-histone H4 K8acetyl (1:1000, ab15823; Abcam). The appropriate secondary antibodies (1:1000, Alexa-Ig; Molecular Probes, Eugene, OR, USA) were used. EdU-positive cells were detected using the Click-iT EdU assay according to the manufacturer's instructions (Thermo Fisher Scientific). Images were captured with a Zeiss Axioimager ApoTome microscope (Carl Zeiss GmbH, Jena, Germany) and processed with Zen software (Zeiss).

\section{RNA isolation and real-time PCR analysis}

Embryonic gonads of 2 litters (2 pregnant mice/condition and experiment) were separated from the mesonephros and pooled by sex. Specifically, 13 to 24 gonads were processed for each experiment $(n=4)$. For postnatal stages, testes $(n=6-10$ / condition) were pooled to get 3 independent groups; control and F0AI adult testes were processed independently $(n=4 /$ condition from different animals). RNA was extracted from gonads using Trizol (Thermo Fisher Scientific). Real-time reverse transcription PCR was performed as previously described (35). For each experiment, 2 independent reverse transcriptase (SuperScriptIV; Thermo Fisher Scientific) reactions and 3 PCR runs were performed on a LightCycler 480 (Roche Diagnostics, Indianapolis, IN, USA). Rps29 was used as the reference gene for data normalization of embryonic gonads (42) and $18 S$ for data normalization of postnatal/adult samples. Primer sequences are as follows: So 9 , forward, 5'-TCGGACACGGAGAACACC-3', reverse, 5'-GCACACGGGGAACTTATCTT-3'; Sox2, forward, 5'TGGGCTCTGTGGTCAAGTC-3', reverse, 5' ${ }^{\prime}$-TGATCATGTCCCGGAGGT-3'; Cdkn1a (p21), forward, 5'-AACATCTCAGGGCCGAAA-3', reverse, 5' -TGCGCTTGGAGTGATAGAAA$3^{\prime}$; Cdkn1c (p57), forward, 5'-CAGGACGAGAATCAAGAGCA$3^{\prime}$, reverse, 5'-GCTTGGCGAAGAAGTCGT-3'; $L-P g d s$, forward, 5'-GGCTCCTGGACACTACACCT-3', reverse, 5'-GCACACGGGGAACTTATCTT-3'; mPges-1, forward, 5'-GCACACTGCTGGTCATCAAG-3', reverse, 5' -ACGTTTCAGCGCATCCTC-3'; $H$-Pgds, forward, 5' -CACGCTGGATGACTTCATGT-3' , reverse, 5'-AATTCATTGAACATCCGCTCTT-3'; mPges-2, forward, 5' CCCAGGAAGGAGACAGCTT-3', reverse, 5' -AGGTAGGTCTTGAGGGCACTAAT-3'; c-Pges, forward, 5'-CGAATTTTGACCGTTTCTCTG-3', reverse, 5'-TGAATCATCATCTGCTCCATCT-3'; Akr1b3, forward, 5'-ACAATAAAACTACAGCCCAGGTG-3', reverse, 5'-TCGCTGCTCACCTCAAAGT-3'; Akr1b7, forward, 5' -CCACCTTCGTGGAACTCAG-3', reverse, 5' CTTGGCCTGGGGAAGACT-3'; $17 \beta H s d 3$, forward, 5'-AATATGTCACGATCGGAGCTG-3', reverse, 5'-GAAGGGATCCGGTTCAGAAT-3'; 15-Pgdh, forward, 5'-GCAGGCGTGAACAATGAGA-3', reverse, 5'-GGTCCCACTGATAACAGAAACC3'; Rps29, forward, 5'-TGAAGGCAAGATGGGTCAC-3', reverse, 5'-GCACATGTTCAGCCCGTATT-3'; 18S, forward, 5'GATCCATTGGAGGGCAAGTCT-3', reverse, 5'-CCAAGATCCAACTACGAGCTTT-3'; 3ßHsd, forward, 5'-GACCAGAAACCAAGGAGGAA-3', reverse, 5'-GCACTGGGCATCCAGAAT-3'; Cyp17a1, forward, 5'-CATCCCACACAAGGCTAACA-3', reverse, 5'-CAGTGCCCAGAGATTGATGA-3'; $\mathrm{Ar}$, forward, 5'-CCAGTCCCAATTGTGTCAAA-3', reverse, 5' -TCCCTGCTGTCCAAACG-3'; StaR, forward, 5'-CCACCTTCGTGGAACTCAG-3', reverse, 5'-CTTGGCCTGGGGAAGACT-3'; Scc, forward, 5'-AAGTATGGCCCCATTTACAGG-3', reverse, 5'-TGGGGTCCACGATGTAAACT-3'; LhR, forward, 5'-GATGCACAGTGGCACCTTC-3', reverse, 5' -CCTGCAATTTGGTGGAAGAG-3'; Amh, forward, 5'-GGGGAGACTGGAGAACAGC-3' , reverse, 5'-AGAGCTCGGGCTCCCATA-3'; Tnp1, forward, 5'-AGCCGCAAGCTAAAGACTCA-3', reverse, 5'

\section{NSAID, PG, and steroid measurements by liquid chromatography-tandem mass spectrometry}

Pregnant females were humanely killed and embryonic gonads (without mesonephros) and liver dissected $30 \mathrm{~min}$ after the second gavage of the day, APAP, ASA, and IBU, respectively, for $\mathrm{APAP}+\mathrm{APAP}, \mathrm{APAP}+\mathrm{ASA}$, and APAP + IBU treatments. For each condition, APAP, ASA, and IBU were quantified by liquid chromatography-tandem mass spectrometry (LC-MS/MS) in plasma from pregnant mice $(n=2)$ and in livers from male 13.5 dpc embryos (100-310 mg from 2 littermates). Embryo livers were homogenized in water using the Precellys (Bertin Technologies, Montigny-le-Bretonneux, France). Then $50 \mu 1$ of each plasma or liver sample was added to $200 \mu \mathrm{l}$ of acetonitrile with $2 \%$ of ammonia, vortexed for $15 \mathrm{~s}$, and centrifuged at $4^{\circ} \mathrm{C}$ for $15 \mathrm{~min}$. Supernatants were transferred to fresh tubes and evaporated to dryness using a Turbovap LV Evaporator (Biotage, Hengoed, United Kingdom). Extracts were resuspended in $50 \mu l$ of water with $0.2 \%$ ammonia. IBU and APAP were quantified by linear regression with $1 / x^{2}$ weighing and a range from 25 to 5000 and 5 to $500 \mathrm{ng} / \mathrm{ml}$, respectively. Salicylic acid was measured using quadratic regression with $1 / x$ weighing and a range of 25 to $2500 \mathrm{ng} / \mathrm{ml}$. Each sample $(10 \mu \mathrm{l})$ was injected in the LC-MS/ MS system, which included a Waters Acquity ultraperformance liquid chromatography-tandem mass spectrometry (UPLC) system with an Acquity UPLC BEH phenyl $1.7 \mu \mathrm{m}, 2.1 \times 100-\mathrm{mm}$ column and a reversed-phase gradient over a run time of $5 \mathrm{~min}$ (Waters, Milford, MA, USA).

$\mathrm{PGD}_{2}, 15$-desoxy 12, 14-PGJ2, PGE 2 , PGF2 $\alpha$, 6-keto-PGF1 $\alpha$ $\left(\mathrm{PGI}_{2}\right)$, and thromboxane (TXA2) were quantified in $13.5 \mathrm{dpc}$ control and APAP + IBU-treated testes by LC-MS/MS. For this experiment, 200 control and 210 exposed testes were isolated from embryos of 15 controls and 15 APAP + IBU-treated pregnant females and then pooled. Testes were homogenized in methanol containing $\mathrm{PGD}_{2}-\mathrm{d} 4$ and $\mathrm{PGE}_{2}-\mathrm{d} 4$ as internal standards using the Precellys device (Bertin Technologies). Homogenates were centrifuged at $20,000 \mathrm{~g}$ for $10 \mathrm{~min}$, and supernatants 
were evaporated and resuspended in $100 \mu l$ of $0.1 \%$ acetic acid in water/acetonitrile/isopropanol, 80/18/2, v/v/v. $\mathrm{PGD}_{2}, 15-$ desoxy 12,14-PGJ2, PGE 2 , PGF2a, PGI 2,6 -keto-PGF1 $\alpha$, and TXA2 were quantified by linear regression with $1 / x^{2}$ weighing and a range from 1 to $500 \mathrm{ng} / \mathrm{ml}$. Ten microliters of extract was injected in the LC-MS/MS system, which included a Waters Acquity UPLC system with an Acquity UPLC BEH Shield $1.7 \mu \mathrm{m}, 2.1 \times$ $100-\mathrm{mm}$ column, and a reversed-phase gradient with a run time of $5 \mathrm{~min}$. The initial conditions were as follows: mobile phase A $(0.1 \%$ acetic acid) and mobile phase $B$ (acetonitrile/isopropanol, $90 / 10$ ) with a column temperature of $50^{\circ} \mathrm{C}$ and a flow rate of $0.400 \mathrm{ml} / \mathrm{min}$ between 0 and $2 \mathrm{~min}$ and $0.5 \mathrm{ml} / \mathrm{min}$ between 2 and $5 \mathrm{~min}$.

Steroids (testosterone and its precursors $17 \alpha$-hydroxy progesterone and androstenedione) were quantified in 3 mo old control $(n=5)$, F0AI $(n=5)$ and F1AI-AI $(n=6)$ testes by LC-MS/ MS. Adult testes were homogenized in methanol containing mixed internal standards $\left({ }^{2} \mathrm{H}_{7}\right.$-delta4-androstenedione, ${ }^{2} \mathrm{H}_{4}$ testosterone, and ${ }^{2} \mathrm{H}_{8}$-17-hydroxyprogesterone). After evaporation, dried residues were resuspended in $600 \mu l$ of methanol, loaded onto an Oasis Prime HLB (Waters) cartridge, and sequentially washed with $0.1 \%$ formic acid in $35 \%$ methanol and $0.1 \%$ ammonia solution in 35\% methanol. Samples were eluted with $45 \mu \mathrm{l}$ of methanol and then diluted with $55 \mu \mathrm{l}$ of distilled water. After mixing, $30 \mu \mathrm{l}$ were injected for UPLC analysis.

\section{Sperm analysis}

The IVOS I computer-assisted semen analyses (CASA) system (Hamilton Thorne, Beverly, MA, USA) was used for semen concentration and motility assessment. Both cauda epididymis were immersed and chopped with small scissors into $100 \mu \mathrm{l}$ of Tris-citric-fructose buffer. After incubation at $37^{\circ} \mathrm{C}$ for $10 \mathrm{~min}$ for sperm release, sperm cells were collected from the epididymis tissue. A $4 \mu \mathrm{l}$ aliquot was placed into a standardized 4-chamber Leja counting slide (Leja Products, Nieuw-Vennep, The Netherlands). The IVOS settings chosen was those defined for mice sperm-cell analysis (by Hamilton Thorne): a total of 30 frames were captured at $60 \mathrm{~Hz}$, with software settings as follows: cell detection with a minimum contrast of 50 , a minimum cell size of 4 pixels, and a cell intensity of 80 . The recorded CASA parameters include the average path velocity (VAP), straight line velocity (VSL), curvilinear velocity (VCL), amplitude of lateral head displacement, motility (percentage), and sperm concentration $\left(10^{6} / \mathrm{ml}\right)$. The cutoff value for progressive cells was as follows: for VAP (50 $\mu \mathrm{m} / \mathrm{s}$ ) and for straightness (STR; 80.0\%); slow cells were recorded as static and were assigned a VAP cutoff of $7.4 \mu \mathrm{m} / \mathrm{s}$ and a VSL cutoff of $6.6 \mu \mathrm{m} / \mathrm{s}$. With an automated stage, $10 \mathrm{mi}-$ croscope fields were analyzed using the predetermined starting position within each chamber. Statistical analyses were performed using the mean of the 10 analyzed fields with at least 500 cells. The normality of the parameters was verified via the Shapiro-Wilk test, and a variance comparison analysis (ANOVA) was performed with the GLM procedure in SAS software (SAS Institute, Cary, NC, USA).

\section{mRNA expression profiling and analysis}

Cytoplasmic and mitochondrial rRNAs were removed from $275 \mathrm{ng}$ of total RNA using the Ribo-Zero Gold Depletion Kit (Illumina, San Diego, CA, USA) according to the manufacturer's instructions. The rRNA-depleted RNA was purified using the Agencourt RNAClean XP Kit (Beckman Coulter, Brea, CA, USA), and libraries were prepared with the TruSeq Stranded Total RNA Sample Prep Kit (Illumina) according to the manufacturer's instructions. This includes a first-strand synthesis, a second-strand synthesis, end repair, A tailing, adapter ligation, and a final PCR step. Amplified libraries were purified using the Agencourt XP Kit (Beckman Coulter).

The RNA-Seq library quality was evaluated by on-chip electrophoresis (DNA 1000 chip) of $1 \mu$ l of each sample on an Agilent 2100 Bioanalyzer (Agilent Technologies, Santa Clara, CA, USA). The library DNA concentration was estimated using Qubit 2.0 with the DNA HS Assay (Thermo Fisher Scientific). RNA-Seq libraries were pooled in 4-nM stocks, denatured, and diluted to $1.2 \mathrm{pM}$. Libraries were sequenced (75 bp reads) in a paired-end format on a NextSeq 500 instrument (Illumina).

The BCL files were converted to FastQ format by Bcl2fastq v.2.17 software (Illumina) for analysis. Sequence data were checked with the FastQC tool (http://www.bioinformatics. babraham.ac.uk/projects/fastqc/).

Genome sequences and gene annotations were downloaded from Ensembl (GRCm38, release 84; ftp://ftp.ensembl.org/pub/ release-84/fasta/mus_musculus/dnal, ftp://ftp.ensembl.org/pub/ release-84/gff3/mus_musculus/). SAMtools v.1.3 $(43,44)$, Bowtie v.2.2.6 (45), TopHat v2.1 (46), and Cufflinks v.2.2.1 $(47,48)$ were downloaded (http://wwww.htslib.org/, http://bowtie-bio.sourceforge. net, https://ccb.jhu.edu/software/tophat, and http://cole-trapnell-lab. github.io/cufflinks, respectively) and installed on a Linux server following their software instruction manuals.

Paired-end reads were aligned to the reference genome (GRCm38) with Bowtie2 and TopHat. The Cufflinks suite of tools was used to quantify gene expression and for comparison of transcript expression levels. Results were visualized and analyzed with the R (R Foundation for Statistical Computing, Vienna,

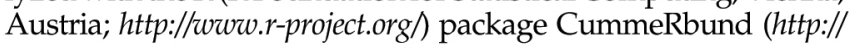
compbio.mit.edu/cummeRbund/).

\section{Statistical analysis}

Statistical analyse were performed by Prism 7 (GraphPad Software, La Jolla, CA, USA). The Student's $t$ test was used to compare 2 groups in independent experiments and the 1-way ANOVA test with Geisser-Greenhouse correction and the Tukey's post hoc test for multiple comparisons [real-time quantitative RT-PCR (qRT-PCR) experiments and cell counting]. Results were considered statistically significant at $P<0.05$. For CASA data on sperm parameters, statistical analysis was performed by SAS 9.4 software (SAS Institute, Cary, NC, USA). Differences between mice groups were assessed by using the general linear model procedure (proc GLM) and considered significant at $P \leq 0.05$.

\section{RESULTS}

\section{In utero exposure to NSAIDs and APAP impairs male germ-cell, but not somatic-cell, proliferation in mouse embryonic gonads}

In the mouse, Sertoli-cell differentiation starts shortly after the onset of Sox 9 expression, which is induced by the testisdetermining factor SRY (49). Meanwhile, primordial germ cells that have reached the gonadal ridge by $10.5 \mathrm{dpc}$ proliferate up to $13.5 \mathrm{dpc}$. Concomitant with pluripotency gene repression and mitotic arrest, primordial germ cells differentiate into prospermatogonia between 13.5 and $15.5 \mathrm{dpc}$ (50). To evaluate the effect of NSAIDs or APAP exposure on these early events, $30 \mathrm{mg} / \mathrm{kg} / \mathrm{d}$ APAP, $50 \mathrm{mg} / \mathrm{kg} / \mathrm{d}$ ASA, $15 \mathrm{mg} / \mathrm{kg} / \mathrm{d}$ IBU, or diluent alone (9.7\% ethanol, control) was individually administered by gavage to pregnant mice between 10.5 and $13.5 \mathrm{dpc}$. This 
period corresponds to the last part of the first trimester of gestation in humans (6-10 wk). Immunofluorescence analysis of $13.5 \mathrm{dpc}$ male gonad sections using antibodies against Sox9 (Sertoli-cell marker) and Vasa/Mvh (germ-cell marker) did not highlight any difference in testis cord formation after in utero exposure to each of the 3 drugs compared to control (Fig. 1A). Coimmunofluorescence analysis after EdU labeling showed that
A
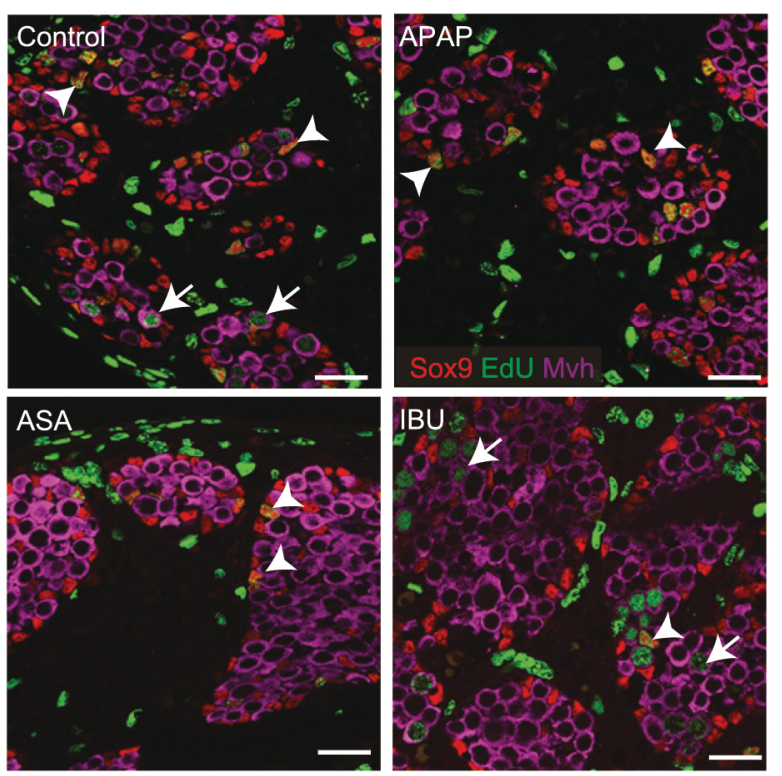
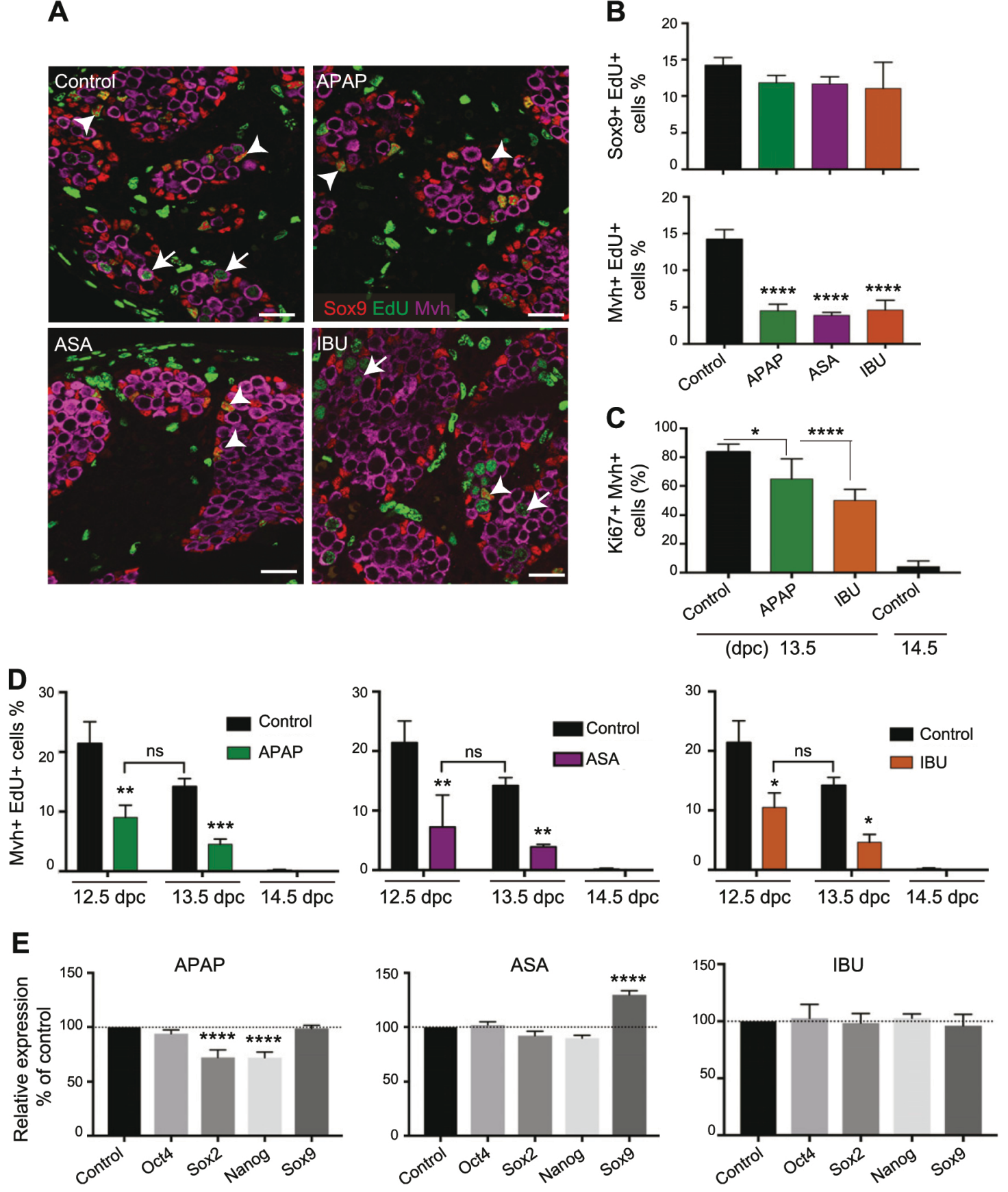

Figure 1. Exposure to APAP, ASA, or IBU decreases germ-cell proliferation. A) Representative immunofluorescence images of testes from mouse 13.5 dpc embryos, mothers of which were treated with ethanol (control), APAP, ASA, or IBU between 10.5 and 13.5 dpc and pulsed with EdU at 13.5 dpc; Sox9 (Sertoli-cell marker) in red, Vasa/Mvh (germ-cell marker) in purple, and EdU in green (scale bar, $100 \mu \mathrm{m}$ ). Arrows and arrowheads highlight proliferating EdU ${ }^{+}$germ cells and EdU ${ }^{+}$Sertoli cells, respectively. $B$ ) Quantification of Sox $9^{+} \mathrm{EdU}^{+}$and $\mathrm{Mvh}^{+} \mathrm{EdU}^{+}$cells in control and treated testes; data are percentage of proliferating EdU $\mathrm{U}^{+}$cells among all Sox $9^{+}$or all $\mathrm{Mvh}^{+}$cells. C) Quantification (percentage) of Ki-67 $7^{+}$cells among all $\mathrm{Mvh}^{+}$cells in 13.5 and $14.5 \mathrm{dpc}$ control and $13.5 \mathrm{dpc}$ in utero-exposed testes. $B, C$ ) Values are means \pm SEM for $n=6$ gonads/group; 700 to 2100 counted cells for each data point. D) Percentage of proliferating EdU ${ }^{+}$cells among all $\mathrm{Mvh}^{+}$cells in control and in utero-exposed testes at 12.5 , 13.5, or $14.5 \mathrm{dpc}$; pregnant females were pulsed with EdU $2 \mathrm{~h}$ before dissection. Values are means \pm SEM for $n=3-6$ gonads/group and 80 to 870 counted cells for each point. E) qRT-PCR analysis of Oct4, Nanog, Sox2, and Sox9 expression levels normalized to Rps 29 expression and presented as percentage of expression in control 13.5 dpc testes (set to 100 ). $* P<0.05, * * P<0.01, * * * * P<$ $0.0001(B-E)$. 
the percentage of S-phase cells was significantly reduced in germ cells $\left(\mathrm{Mvh}^{+} \mathrm{EdU} \mathrm{U}^{+}\right)$, but not in Sertoli cells $\left(\right.$ Sox $\left.9^{+} \mathrm{EdU}^{+}\right)$, in in utero-exposed gonads compared to control (Fig. 1A,B). Accordingly, the proliferative index of germ cells $\left(\mathrm{Ki}-67^{+} \mathrm{Mvh}^{+}\right)$was significantly lower in in utero-exposed than in control $13.5 \mathrm{dpc}$ gonads (Fig. 1C). However, the tubular diameter, the total number of Sertoli or germ cells per tubule, and the apoptotic index did not vary between in utero-exposed and control 13.5 dpc gonads (unpublished observations). Moreover, the percentage of S-phase germ cells $\left(\mathrm{Mvh}^{+} \mathrm{EdU}^{+}\right)$in in utero-exposed $12.5 \mathrm{dpc}$ gonads was comparable to that of 13.5 dpc controls (Fig. 1D). This suggests that in utero exposure to APAP, ASA, or IBU might advance germ-cell mitotic arrest. In agreement, expression of the pluripotent genes Sox2 and Nanog was significantly lower in APAP (but not in ASA or IBU) exposed gonads compared to controls (Fig. 1E). However, expression of the Sertoli differentiating marker Sox9 is increased only in $13.5 \mathrm{dpc}$ gonads exposed in utero to ASA (but not to APAP or IBU) (Fig. 1E).

Because NSAIDs (particularly ASA and IBU) and APAP are used together by nearly $4 \%$ of pregnant women (12), the APAP + ASA and APAP + IBU combinations were administered to pregnant mice between 10.5 and 13.5 dpc to evaluate their effects on the differentiation of testis somatic and germ cells in male embryos. Controls received ethanol or a double dose of APAP (APAP + APAP). Immunofluorescence analysis using antibodies against Sox 9 and Vasa/Mvh indicated that testis cords were normally formed in testes from in utero-exposed and control 13.5 dpc male embryos (Fig. 2A). However, coimmunofluorescence experiments after in vivo EdU labeling of pregnant females showed that the percentage of S-phase germ cells $\left(\mathrm{Mvh}^{+} \mathrm{EdU}^{+}\right)$, but not of Sertoli cells $\left(\mathrm{Sox}^{+} \mathrm{EdU}^{+}\right)$, was significantly reduced in gonads from $13.5 \mathrm{dpc}$ embryos exposed to APAP + ASA or APAP + IBU compared to controls (Fig. 2A, B). Exposure to APAP alone (APAP + APAP) did not have any significant effect in both cell types, possibly because of the accelerated APAP metabolism in liver in the presence of high ethanol concentration (diluent), resulting in a weaker concentration of available drug, as previously described (51). Moreover, the germcell proliferation index $\left(\mathrm{Ki}-67^{+} \mathrm{Mvh}^{+}\right.$cells) was significantly higher in $13.5 \mathrm{dpc}$ gonads from embryos exposed in utero to APAP + ASA or APAP + IBU than in controls, suggesting an accumulation of germ cells in the $G_{1}$ phase of the cell cycle (Fig. 2C). Finally, Sox9 was significantly up-regulated and Sox2 (pluripotency gene) downregulated in APAP + IBU testes. Cdkn1a and Cdkn1c, 2 genes that encode the cell cycle inhibitors p21 and p57, were up-regulated in APAP + ASA and APAP + IBU testes, respectively (Fig. 2D). Similar to the results with single drugs, these data are consistent with early embryonic germ-cell mitotic arrest and concomitant decreased cell proliferation in APAP + ASA and APAP + IBU embryonic testes. They also suggest that APAP and IBU may interact with each other to affect cell differentiation in the embryonic testis.

To confirm that APAP and NSAIDs can cross the placental barrier $(10,11)$, first the plasma concentrations of
$\mathrm{APAP}, \mathrm{ASA}$, and IBU were measured in pregnant mice humanely killed $30 \mathrm{~min}$ after APAP, ASA, and IBU treatment (1070, 28,600, and $520 \mathrm{ng} / \mathrm{ml}$, respectively) (Fig. 2E). APAP plasma concentration was similar to what reported in a human testis xenograft mouse model after administration of therapeutic doses of APAP $(740 \mathrm{ng} / \mathrm{ml})(19)$. The concentration of APAP, ASA, and IBU in male embryo livers (611, 4648, and $105 \mathrm{ng} / \mathrm{g}$, respectively) confirmed that embryos were exposed to these chemicals after oral administration to their mothers (Fig. 2E). Residual APAP was detected in the liver of control embryos from mothers treated with ethanol (61.4 ng/g) or PBS (35 ng/g) (Fig. 2E) due to residual APAP in the drinking water $(51 \mathrm{ng} / \mathrm{L})$ of our animal care facility (unpublished observations), which is consistent with data reporting APAP presence in the urine of various populations (52). Because NSAIDs and APAP can pass through the placental barrier after oral administration (Fig. 2E) and target COXs, PG production was assessed in control and APAP + IBU in utero-exposed testes. As a result of its short half-life, $\mathrm{PGI}_{2}$ production is typically monitored by measuring the 6-keto-PGF1 $\alpha$ metabolite, which is a biologically inactive hydration product (53). $\mathrm{PGD}_{2}, \mathrm{PGE}_{2}$, and 6-keto-PGF1 $\alpha$ production was decreased by 22,37 , and $63 \%$, respectively, in $13.5 \mathrm{dpc}$ APAP + IBU exposed testes compared to control (Fig. $2 F$ ). However, 15-desoxy-PGJ2, an active $\mathrm{PGD}_{2}$ metabolite, PGF2 $\alpha$, and TXA2 could not be detected in control and exposed testes. qRT-PCR analysis of genes involved in PG synthesis showed weak expression of prostaglandinendoperoxide synthase 2 (Cox-2), prostaglandin E synthase (Pges)-1, and aldo-keto reductase family 1 , member B7 (Akr1b7) (encoding one of the PGF2 $\alpha$ synthases) and stronger expression of the genes encoding the other PG synthases and of 15-hydroxyprostaglandin dehydrogenase (15-Pgdh), encoding the key PG catabolic enzyme in 13.5 dpc control testes (Fig. 2G). Upon in utero APAP + IBU exposure, hematopoietic prostaglandin D synthase $(\mathrm{H}-$ Pgds), prostaglandin E synthase (Pges)-1, -2, and aldo-keto reductase family 1 , member B7 (Akr1b3) (a second PGF2 $\alpha$ synthase) were significantly up-regulated, and 15-Pgdh down-regulated, compared to control testes (Fig. 2G). This could explain the relatively low decrease in $\mathrm{PGD}_{2}$ and $\mathrm{PGE}_{2}$ production (54). Conversely, APAP + IBU exposure had no effect on prostaglandin-endoperoxide synthase 1 (Cox-1), $C o x-2$, prostaglandin $\mathrm{D} 2$ synthase $(L-P g d s)$, prostaglandin $\mathrm{E}$ synthase 2 (c-Pges), and Akr1b7 expression (Fig. 2G).

\section{In utero exposure to APAP and IBU induces early male germ-line differentiation}

Transcriptome analysis was then performed to identify the genes deregulated in $13.5 \mathrm{dpc}$ male gonads after in utero exposure to APAP and IBU or ASA. Compared to controls, 40,20 , and 122 genes were differentially expressed in $\mathrm{APAP}+\mathrm{APAP}$ ( 3 up- and 37 down-regulated), APAP + ASA (5 up- and 15 down-regulated) and APAP + IBU (103 up- and 19 down-regulated) testes $\left(P=5 \times 10^{-5}\right)$, respectively (Fig. 3A and Supplemental Table S1). However, only 5 differentially expressed genes were common to the 3 data sets (Fig. 3B). Categorization of the differentially 

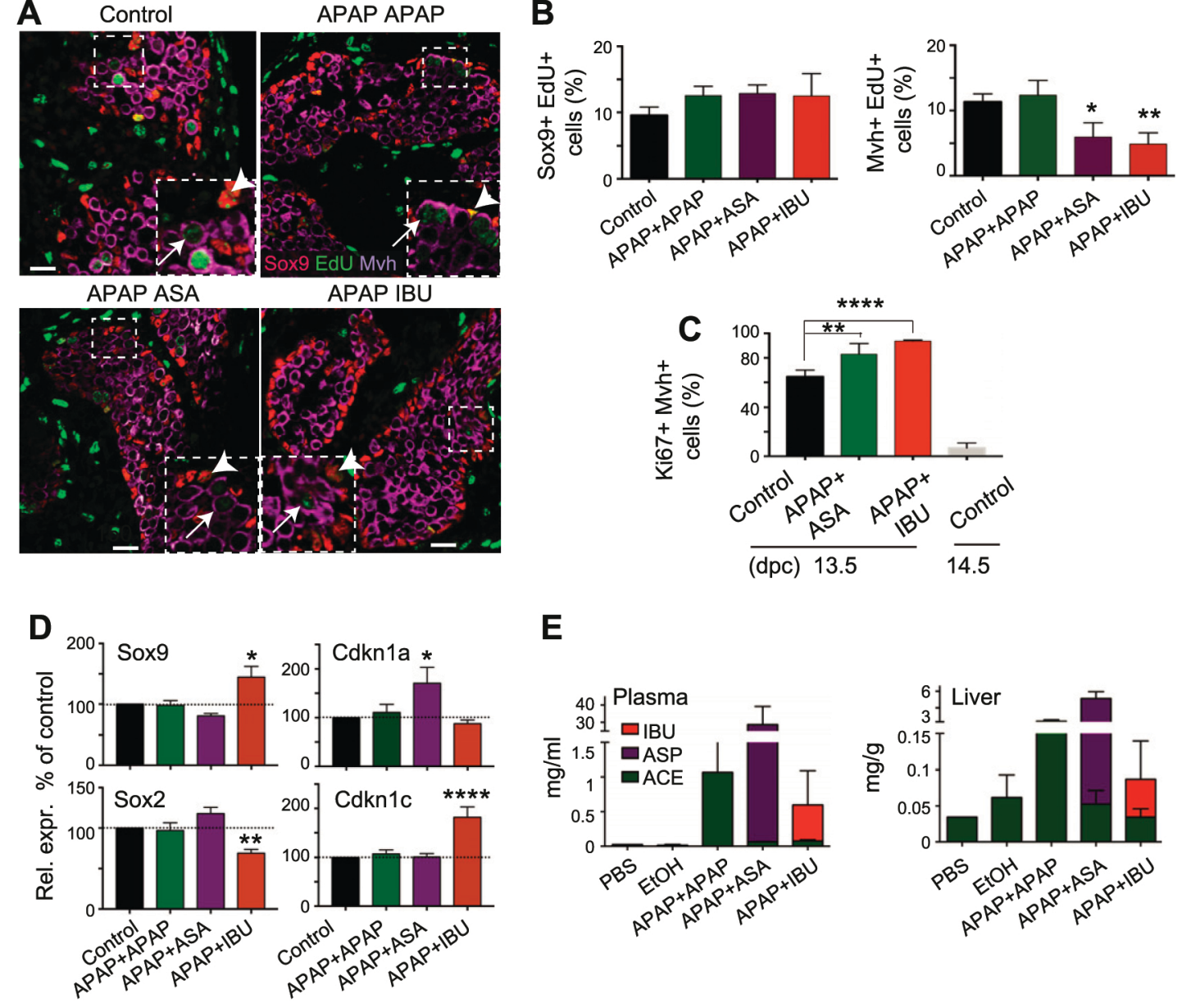

E
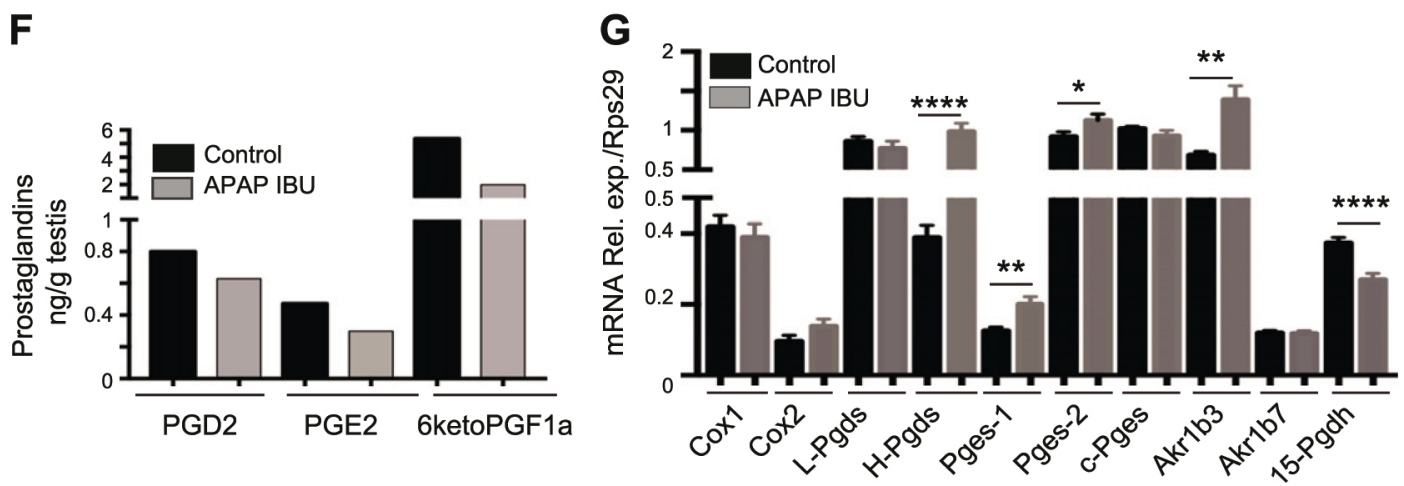

Figure 2. In utero exposure to APAP and NSAIDs decreases germ-cell proliferation. A) Representative immunofluorescence microscopy images of $13.5 \mathrm{dpc}$ testes from embryos exposed in utero to ethanol (control), APAP + APAP, APAP + ASA, or APAP + IBU between 10.5 and $13.5 \mathrm{dpc}$ and pulsed with EdU at $13.5 \mathrm{dpc}$; Sox9 (Sertoli-cell marker) in red, Vasa/Mvh (germcell marker) in purple, and EdU in green (scale bar, $100 \mu \mathrm{m}$ ). Insets show EdU ${ }^{+}$germ cells (arrows) and Sertoli cells (arrowheads). B) Quantification of Sox $9^{+} \mathrm{EdU}^{+}$and $\mathrm{Mvh}^{+} \mathrm{Ed \textrm {U } ^ { + }}$ cells in control and treated testes; data are represented as percentage relative to all Sox $9^{+}$and $\mathrm{Mvh}^{+}$cells. $C$ ) Percentage of $\mathrm{Ki}-67^{+}$cells among all $\mathrm{Mvh}^{+}$cells in 13.5 and $14.5 \mathrm{dpc}$ control and 13.5 dpc exposed testes. $B, C$ ) Values are means \pm SEM for $n=15-22$ gonads in each group and 500 to 2000 counted cells for each data point. D) qRT-PCR analysis of Sox9, $C d k n 1 a, C d k n 1 c$, and Sox 2 expression in 13.5 dpc testes. Data were normalized to Rps 29 expression and are presented as percentage of expression in control testes (set to 100). Data are means \pm SEM, $n=4$ experiments. E) APAP, ASA, and IBU concentrations in plasma of control, PBS, APAP + APAP, APAP + ASA, and APAP + IBU treated pregnant females and in liver of their male embryos (mean \pm SEM of 2 experiments). $F$ ) Dosage of PGD DGE $_{2}$ and $6-$ keto-PGF1 $\alpha\left(\mathrm{PGI}_{2}\right)$ by mass spectrometry in $13.5 \mathrm{dpc}$ control and APAP + IBU exposed testes $(n=1$ pool of 200 and 210 gonads, respectively). G) qRT-PCR analysis of genes encoding factors involved in PG synthesis in 13.5 dpc control and APAP + IBU exposed testes; data were normalized to Rps 29 expression and are shown as means \pm sEM; $n=3$ experiments. $* P<0.05$, $* * P<0.01, * * * * P<0.0001(B-D, G)$. 

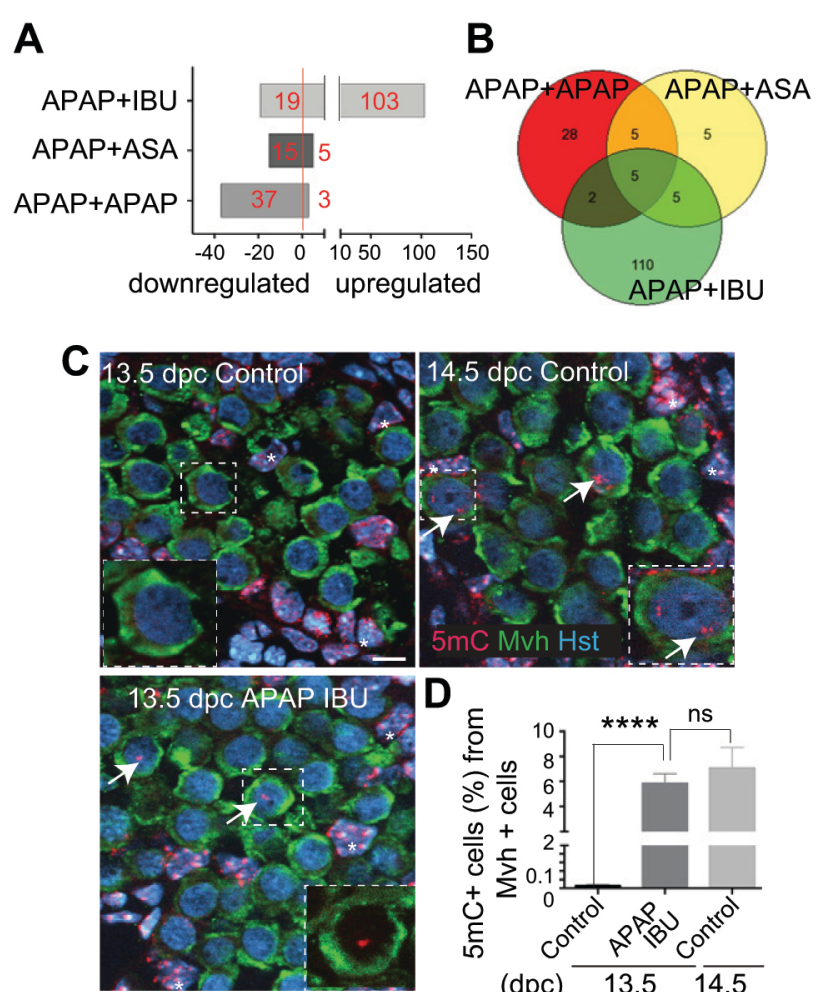

E

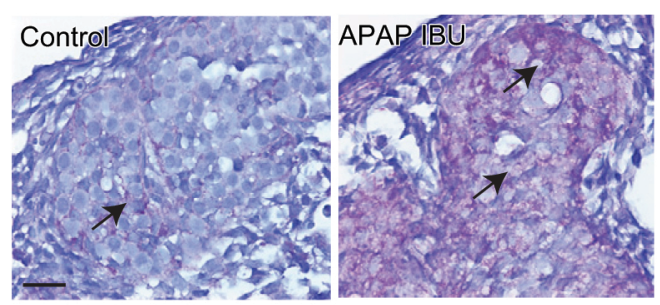

Figure 3. Exposure to APAP and IBU leads to early germ-cell differentiation through early 5-mC deposition and increased ECM protein secretion. A) Number of genes that are expressed in embryonic testes and significantly deregulated (at least 1.5fold change) in APAP + APAP, APAP + ASA, or APAP + IBU exposed 13.5 dpc testes compared to control. Number of downor up-regulated genes is indicated in red. These data are accessible through GEO Series accession number GSE89061 (http://www.ncbi.nlm.nih.gov/geo/query/acc.cgi?acc=GSE89061). B) Venn diagram showing overlap of genes that are differentially expressed in 3 different experimental conditions. C) Coimmunofluorescence analysis of DNA methylation (anti-5-mC antibody, red) in germ cells (anti-Vasa/Mvh antibody, green) in 13.5 and $14.5 \mathrm{dpc}$ controls and $13.5 \mathrm{dpc}$ APAP + IBU exposed testes; nuclei are stained with Hoechst (Hst, blue). Arrows highlight 5-mC staining in germ cells; insets show high-magnification images of boxed areas. D) Quantification of $5-\mathrm{mC}^{+}$germ cells (percentage of all $\mathrm{Mvh}^{+}$cells) in $13.5 \mathrm{dpc}$ control and APAP + IBU exposed testes and $14.5 \mathrm{dpc}$ control testes. Values are means \pm SEM for $n=10$ gonads in each group and 50 to 120 counted germ cells/gonad; ns, not significant. $* * * * P<0.0001$. E) PAS staining of $13.5 \mathrm{dpc}$ control and APAP + IBU exposed testes. Arrows highlight glycoproteins deposits within testis cords. Scale bars, $25 \mu \mathrm{m}$ $(C)$ and $50 \mu \mathrm{m}(D)$.

expressed genes using the ToppGene program (55) and Gene Ontology analysis showed that APAP + APAP and APAP + ASA influenced similar molecular, biologic, and cellular functions/pathways (Supplemental TableS2).
Conversely, the APAP + IBU combination affected genes involved in transcriptional regulation activity, extracellular matrix (ECM) regulation, organ morphogenesis, and the TGF- $\beta$ signaling pathway (Supplemental Table S2), suggesting different mechanisms of action for the APAP + IBU combination compared to APAP or APAP + ASA.

We focused on the analysis of the 122 transcripts (96 genes) deregulated by in utero exposure to APAP + IBU using data from the National Center for Biotechnology Information Gene Expression Omnibus (GEO; Bethesda, MD, USA; https://www.ncbi.nlm.nih.gov/geo/) data set browser (data set record GDS3995) (56). In this group, 14 femalespecific and 13 male-specific genes were up-regulated (Supplemental Table S3), as were several homeobox genes (Supplemental Tables S2 and S3). Moreover, Sox2 (0.53-fold), the nodal male inhibitor Lefty1 (left right determination factor 1) (0.48-fold) that is required for pluripotency maintenance (57) and Sohlh2 (spermatogenesis and oogenesis specific basic helix-loop-helix 2) (0.56-fold) that encodes a c-Kit regulator in the germ line (58) were among the 12 down-regulated genes (Supplemental Table S3). Conversely, 2 main testis-differentiating genes [Sox9, $>1.6$-fold; and Dnmt3L (DNA (cytosine-5-)-methyltransferase 3-like), >3.5-fold, which encodes the enzyme involved in male germ-line reprogramming] were up-regulated (Supplemental Tables S1 and S3). Induction of expression of de novo DNA methylases (Dnmts), including Dnmt3L, in male germ cells coincides with the reestablishment of DNA methylation $(5-\mathrm{mC})$ at $14.5 \mathrm{dpc}$. Particularly, CpG island methylation of the Sox2 and Nanog promoters (59) occurs concomitantly with germ-line differentiation onset (60). Immunofluorescence analysis with an anti-5-mC antibody showed that in $13.5 \mathrm{dpc}$ APAP + IBU gonads, $6 \%$ of germ cells $\left(\mathrm{Mvh}^{+}\right)$were 5-mC positive, as in $14.5 \mathrm{dpc}$ control gonads. Conversely, methylation could not be detected in $13.5 \mathrm{dpc}$ control testes (Fig. 3C, D). This suggests that $\mathrm{APAP}+\mathrm{IBU}$ exposure promotes earlier germ-line 5-mC deposition through Dnmt3L expression up-regulation. In utero APAP + IBU exposure also deregulated 22 genes that encode ECM proteins (Supplemental Table S4), particularly different collagen types (Col2a1, Col9a1, Col11a1a2, Col12a1), and glycoproteins or proteoglycans such as aggregan (Acan), versican (Vcan), lumican (Lum), matrilin3 (Matn3), testatin (Cystatin9, Cst9), and keratocan (Kera), most of which are directly activated by Sox 9 in chondrocytes (61) and embryonic testis (62). In agreement, periodic acid-Schiff (PAS) staining showed that glycoprotein accumulation within the testis cords was significantly higher in APAP + IBU than in control 13.5 dpc gonads (Fig. 3E).

\section{In utero exposure to APAP and IBU leads to impaired production of spermatozoa in FO and reduced sperm quality in F1 adults}

To evaluate whether the observed embryonic phenotype affects fertility in adult males, $8 \mathrm{wk}$ old male and $6 \mathrm{wk}$ old female mice that were exposed in utero to APAP + IBU (F0AI) or not (FOWT) were mated to produce F1 animals (Fig. 4A), as follows: male F0AI $\times$ female F0WT (F1AI-WT) $(n=7)$; male F0WT $\times$ female F0AI (F1WT-AI) $(n=15)$; 


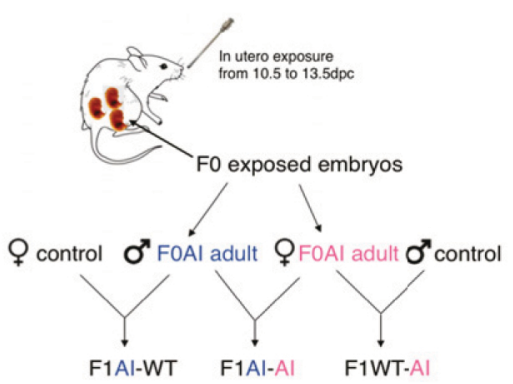

D

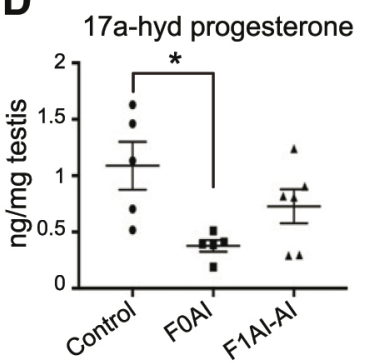

$\mathbf{F}$

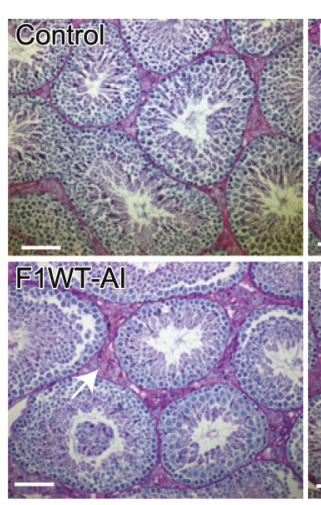

H

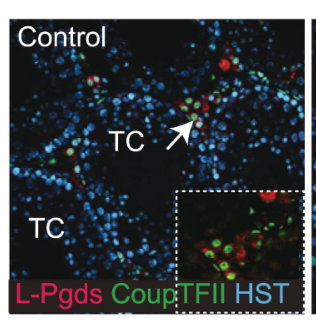

I
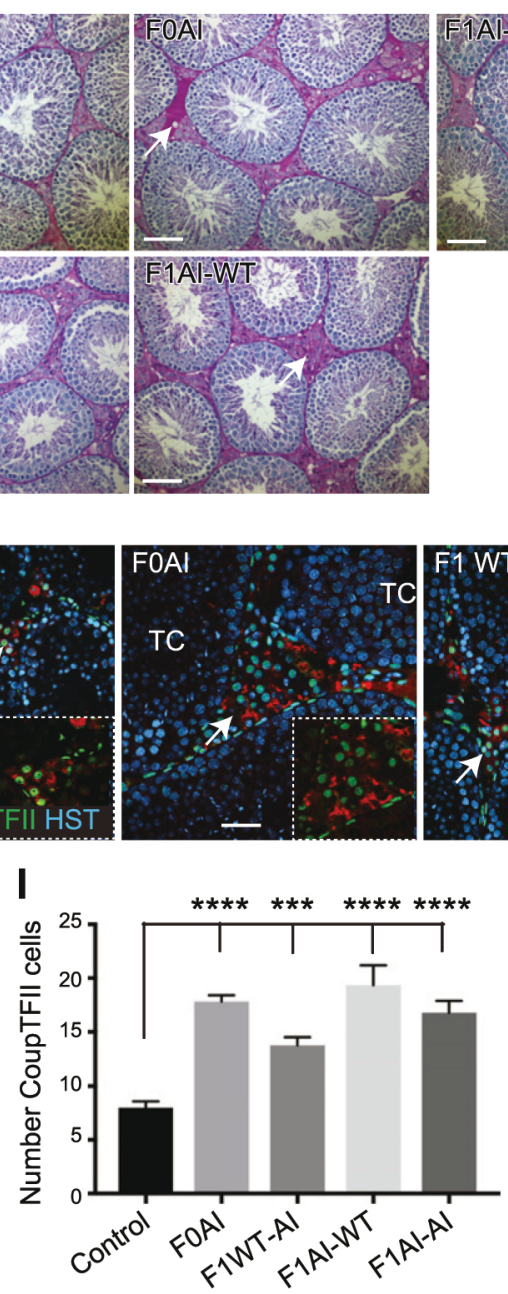
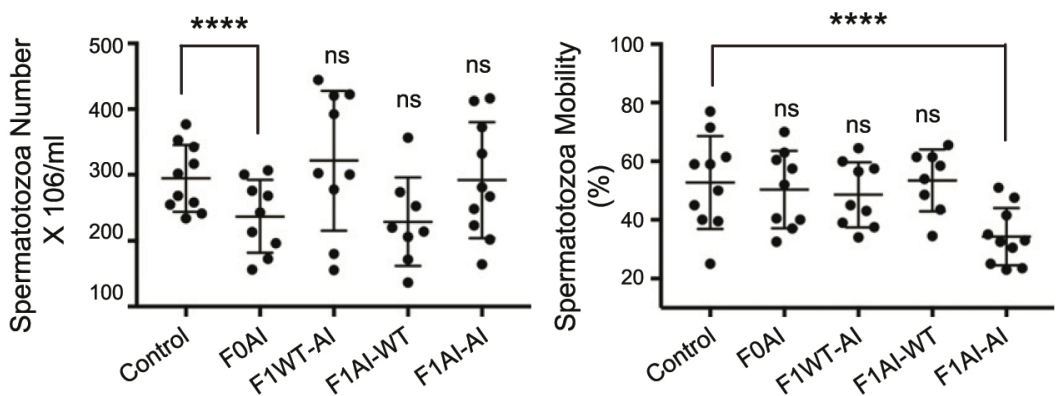

$\mathbf{E}$

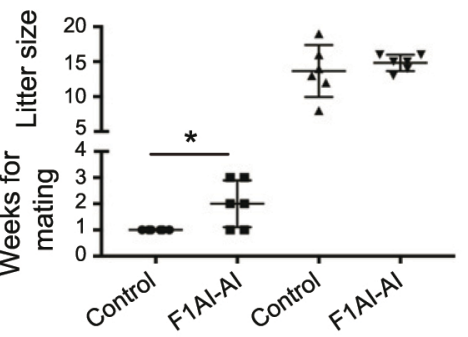

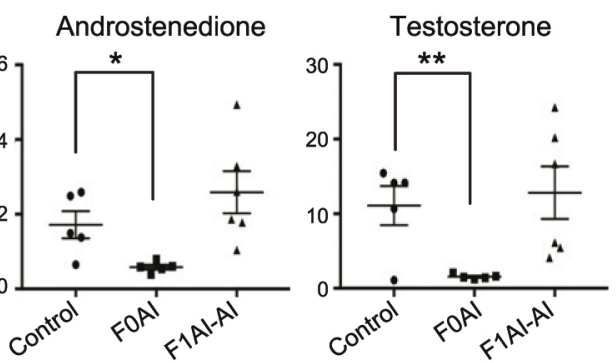
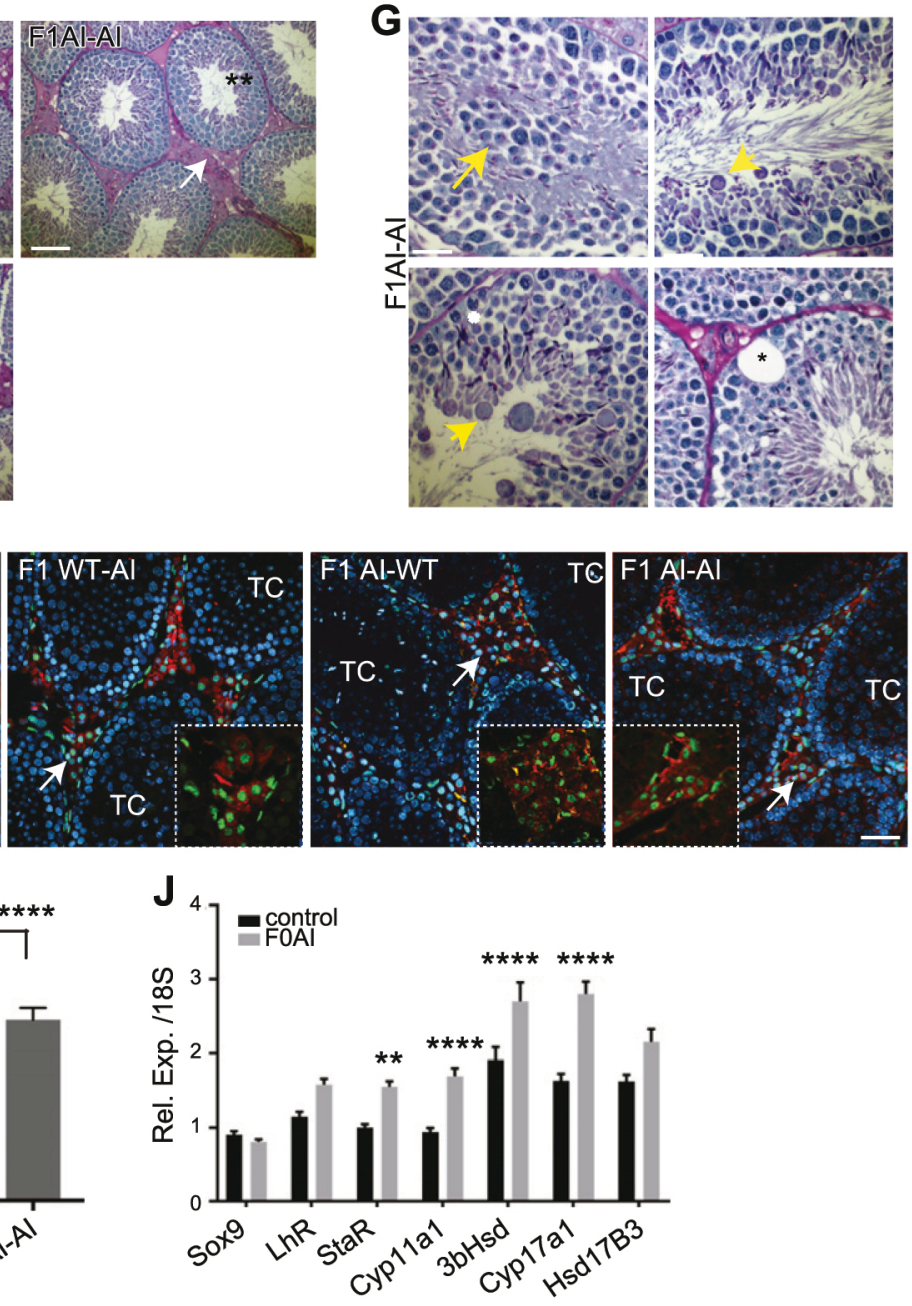

Figure 4. Sperm parameters of F0 mice and F1 adult mice are impaired after in utero exposure to APAP and IBU. A) Schematic representation of F0 mating experiments. $B, C$ ) Number of Spz per both caudal epididymis $(B)$ and percentage of motility $(C)$ in 3 mo old control, F0AI, F1WT-AI, F1AI-WT, and F1AI-AI animals ( $n=8-10$ animals/group). Horizontal middle line represents mean sperm number and motility percentage; ns, no significant difference with control animals. $* * * * P<0.0001 . D$ ) Content of testosterone and its precursors $17 \alpha$-hydroxy progesterone and androstenedione were measured in control, F0AI, and F1AI-AI 
male F0AI $\times$ female F0AI $(\mathrm{F} 1 \mathrm{AI}-\mathrm{AI})(n=19) ;$ male F0WT $\times$ female FOWT (F1WT) $(n=6)$. All females were mated within a week; the frequency of full-term pregnancies (100\%) and the average litter size (between 11 and 18 pups) were comparable, indicating that APAP + IBU exposure did not affect the reproductive ability of adult F0 animals. Because the phenotypes of F1WT and F0WT animals and testes were similar, data from these 2 groups are referred as control in the next experiments.

Quantification using the CASA system of cauda epididymal sperm of 3 mo old F0 and F1 adult males showed that F0AI mice, but not F1 animals, had a significant lower sperm count (19\% decrease) than control mice [mean: $236 \times 10^{6}$ vs. $294 \times 10^{6}$ spermatozoa $(\mathrm{Spz}) / \mathrm{ml}, P=0.0016$, control: $n=10$, F0AI: $n=9$, which corresponds to a production of 23 to $29 \times 10^{6} \mathrm{Spz} /$ animal] (Fig. 4B). The number of Spz in F1AI-WT mice (mean: $228 \times 10^{6} \mathrm{Spz} / \mathrm{ml}$ ) was also reduced, but the difference with control mice was not significant $(P=0.11)$. Analysis of the sperm motion parameters with the CASA system in F0 and F1 adult males showed significantly lower mean values for most motility parameters in F1AI-AI sperm compared to controls, including global motility, which was decreased by $40 \%$ ( $P<$ $0.05, n=8-10$ ) (Fig. 4C and Table 1), and VAP, VSL, and VCL (Table 1). Conversely, lateral head displacement and STR were not affected (Table 1). However, sperm motility was not affected in F0AI, F1WT-AI, and F1AI-WT mice. In utero exposure suppresses intratesticular testosterone by $80 \%$ and its precursors, $17 \alpha$-hydroxy progesterone $(80 \%)$ and androstenedione (60\%), in FOAI adult animals compared to controls (Fig. 4D). Normal steroid production was recovered in $8 \mathrm{wk}$ old F1AI-AI animals (Fig. 4D). These data suggest complex effects of in utero exposure to APAP+ IBU, first acting on spermatogenesis in exposed F0AI animals, possibly through a deficit in testosterone production, and second affecting sperm quality in their offspring when both parents have been exposed in utero (F1AI-AI animals). This defect led to subfertility in 6 mo old F1AI-AI males that mated with a control female after more than $1 \mathrm{wk}(66 \%, n=$ 4 of 6) (Fig. 4E); however, the litter size was similar to that of control males (Fig. 4E).

PAS staining indicated that overall, the histology of seminiferous epithelium in 3 mo old F0 and F1 testes was normal, with the different stages of the seminiferous epithelium cycle represented (Fig. 4F). However, in F1AI-AI seminiferous tubules, abnormal germ-cell characteristics were observed, such as atypical presence of multinucleated cells, sloughed or clustered cells into the lumen, and vacuolization of the basal compartment (Fig. 4G). Furthermore, in F0AI and F1 adult testes, the interstitial compartment was larger than in controls (Fig. 4F). Accordingly, immunofluorescence analysis using antibodies against CoupTFII, a Leydig stem-cell marker (63), and L-Pgds, an adult Leydig cell (ALC) marker $(31,64)$, indicated that the number of Leydig stem cells (Fig. 4H, I) and ALCs (Fig. 4H) was significantly higher in F0 and F1 adult testes compared to controls. Quantification of Leydigcell-specific mRNA transcripts showed a significant increased expression of the genes encoding steroidogenic acute regulatory protein (Star), cholesterol side-chain cleavage enzyme (Scc, Cyp11a1), 3 $\beta$-hydroxysteroid dehydrogenase $(3 \beta-H s d)$, and $17 \alpha$-hydroxylase $/ 17,20$ lyase (Cyp17a1) in F0AI testes compared to controls. The expression of the genes encoding luteinizing-choriogonadotropic hormone receptor $(L h R)$ and 17 $\beta$-hydroxysteroid dehydrogenase 3 (Hsd17 $\beta 3$ ) was also increased in F0AI testes, but the difference with control mice was not significant (Fig. 4J). All together, these data show a significant alteration of testis morphology / function and suggest an hyperplasia of the Leydig cell lineage in in uteroexposed F0AI and also in F1 animals.

\section{Sperm count reduction in in utero-exposed mice could be caused by reduction of spermatogonia A population}

During early postnatal life, embryonic gonocytes/ prospermatogonia differentiate into spermatogonia. This differentiation process is essential for the establishment of the spermatogonia A (SpgA) pool comprising the spermatogonial stem cells and consequently for fertility. The decrease in sperm count in F0 animals suggested that in utero exposure to APAP + IBU could interfere with the postnatal development of germ cells and adult spermatogenesis. To test this hypothesis, testes from F0 animals were analyzed during the first wave of spermatogenesis, at meiosis onset ( $8 \mathrm{dpp}$ ), when the germ-line population includes SpgA, differentiating spermatogonia $\mathrm{B}(\mathrm{SpgB})$, and some preleptotene spermatocytes, at $14 \mathrm{dpp}$ at the time of meiotic prophase I (spermatocytes), at $21 \mathrm{dpp}$ when postmeiotic cell (round spermatid, rSpd) start to appear, and at $30 \mathrm{dpp}$ when spermatids begin to elongate (elongated spermatid, eSpd) (5).

testes ( $n=5-6$ testes/group). Levels of steroids are expressed in $\mathrm{ng} / \mathrm{mg}$ testis; values are means \pm SEM. $* P<0.05, * * P<0.01 . E$ ) Fertility of 6 mo old F1AI-AI males. Number of weeks (1-2 or 3) for mating and litter size after full-term pregnancies are shown for control $(n=5)$ and F1AI-AI $(n=6)$ males. Values are means \pm SEM. ${ }^{*} P<0.05$. F) PAS-stained transversal sections of seminiferous tubules from 3 mo old testes. White arrows indicate interstitial compartment. $G$ ) Enlarged panels of F1AI-AI sections. Yellow arrow shows clustered cells into lumen, yellow arrowheads multinucleated cells and sloughed cells in lumen, and asterisk shows vacuolization of basal compartment. $H, I)$ Leydig-cell population in 3 mo old testes was identified $(H)$ and quantified $(I)$ by immunofluorescence with anti-L-Pgds (in red) and anti-CoupTFII (green) antibodies (arrows), and nuclei were stained with Hoechst (HST, blue); insets show representative images of interstitial compartment with L-Pgds (red) and CoupTFII (green) positive cells. TC, testis cord. Number of Leydig stem cells (CoupTFII ${ }^{+}$) in interstitial space (between 3 tubules) is represented as means \pm SEM for $n=5$ testes/group and $n=5$ representative pictures/testis $(I) . J)$ qRT-PCR analysis of

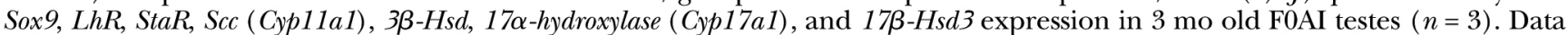
were normalized to $18 \mathrm{~S}$ expression and are presented relative to expression in control testes (set to 1$)$. Data are means \pm SEM $(n=$ 4 experiments). ${ }^{*} P<0.05, * * P<0.01, * * * P<0.005, * * * * P<0.0001$. Scale bars, $200 \mu \mathrm{m}(F), 100 \mu \mathrm{m}(G, H)$. 


\begin{tabular}{lccccc}
\hline \hline Characteristic & Control $($ mean $\pm \mathrm{SD})$ & F0AI $($ mean $\pm \mathrm{SD})$ & FlWT-AI $($ mean $\pm \mathrm{SD})$ & F1AI-WT $(\mathrm{mean} \pm \mathrm{SD})$ & F1AI-AI $(\mathrm{mean} \pm \mathrm{SD})$ \\
\hline Motility $(\%)$ & $52.75 \pm 15.8$ & $50.33 \pm 13.2$ & $48.55 \pm 11.1$ & $53.43 \pm 10.5$ & $34.25 \pm 9.7 * * *$ \\
VAP $(\mu \mathrm{m} / \mathrm{s})$ & $79.02 \pm 13.2$ & $88.84 \pm 13.3$ & $73.28 \pm 7.3$ & $80.22 \pm 9.2$ & $66.83 \pm 8.6^{* * *}$ \\
VCL $(\mu \mathrm{m} / \mathrm{s})$ & $156.46 \pm 24.3$ & $177.55 \pm 23$ & $146.96 \pm 15$ & $161.48 \pm 16.1$ & $134.54 \pm 16^{* * *}$ \\
VSL $(\mu \mathrm{m} / \mathrm{s})$ & $48.61 \pm 7.71$ & $54.39 \pm 8.3$ & $45.53 \pm 5$ & $49.47 \pm 6.3$ & $41.38 \pm 5.8^{* * *}$ \\
STR $(\%)$ & $58.5 \pm 1.39$ & $58.05 \pm 0.52$ & $59.38 \pm 1.4$ & $58.68 \pm 1.4$ & $59.2 \pm 1.9$ \\
Lateral head & $8.82 \pm 0.34$ & $9.03 \pm 0.37$ & $8.5 \pm 0.39$ & $8.63 \pm 0.49$ & $8.43 \pm 0.9$ \\
$\quad$ displacement $(\mu \mathrm{m})$ & & & & & \\
\hline
\end{tabular}

***P<0.005 ( $n=8-10$ testes/group)

Body weight and anogenital distance index (65) were not significantly different in F0AI animals and controls at different time points after birth (Supplemental Fig. S1A, B), which suggests a normal level of fetal androgen exposure in F0 embryos. Similarly, staining with DAPI (a DNA intercalating agent) and fluorescence-activated cell sorting (FACS) analysis revealed that the cell-cycle distribution and $1 \mathrm{~N}, 2 \mathrm{~N}$, and $4 \mathrm{~N}$ DNA content of testis cells was not affected by in utero exposure (Supplemental Fig. S1C). However, incubation with anti-Vasa/Mvh (germ-cell marker) or Lin28a [SpgA marker (66)] antibodies and sorting by FACS showed that the number of germ cells and SpgAs was significantly decreased in F0AI testes at all postnatal stages (except at $30 \mathrm{dpp}$ for $\mathrm{Vasa} / \mathrm{Mvh}^{+}$cells) (Fig. 5A, B). Immunofluorescence with a specific antiLin28a antibody showed a significant decrease in the number of the Lin $28 \mathrm{a}^{+}$cells per tubule in F0AI testes compared to controls (Fig. 5C and Supplemental Fig. S2A), confirming that SpgA number is affected in F0AI animals. In F1 testes, the SpgA number was significantly lower only in 8 and $14 \mathrm{dpp}$ F1AI-WT testes (Fig. 5D). This suggests a transient intergenerational effect of in utero exposure to APAP-IBU on SpgA number.

To analyze meiosis progression, EdU was injected in 8 dpp control and FOAI pups, and animals were humanely killed at $8 \mathrm{dpp}$ ( $2 \mathrm{~h}$ after injection) and at 14, 21, and $30 \mathrm{dpp}$ (1, 2, and 3 wk after EdU injection, respectively). At all stages except $8 \mathrm{dpp}$, the number of EdU $\mathrm{El}^{+}$cells was reproducibly lower in F0AI than control testes (Fig. 5E, I). This suggested that meiosis progression is normal but less efficient in F0AI testes. The normal meiotic progression was confirmed by counting the tubules that contained germ cells at various stages of prophase I, after incubation with an anti- $\gamma \mathrm{H} 2 \mathrm{aX}$ antibody (marker of double-strand DNA breaks occurring in prophase I that shows a dynamic distribution through meiotic I prophase) (Supplemental Fig. S2B). Although meiotic prophase I was not significantly delayed in F0AI testes between 8 and $30 \mathrm{dpp}$, the percentage of tubules containing rSpds at $21 \mathrm{dpp}$ and eSpds at 30 dpp was significantly lower in F0AI testes than controls (Fig. 5F). Similarly, rSpd number per tubule was significantly lower in F0AI testes compared to controls at these stages (Supplemental Fig. S1D, E). These defects were observed also in F1WT-AI, F1AI-WT, and F1AI-AI animals (Fig. 5G, $H$ ). These results suggest that spermatogenesis is less efficient in in utero-exposed animals (F0) and also in their offspring (F1), although in F1 animals the SpgA number was back to normal in late postnatal stages, and consequently sperm count was not significantly affected.

\section{Delayed Sertoli-cell maturation could contribute to effect on sperm count}

Comparison of the transcriptome profiles of in uteroexposed $13.5 \mathrm{dpc}$ testes and controls (Fig. $3 A, B$ and Supplemental Tables S1 and S3) and the decrease in sperm count in F0 animals (Fig. 4B) suggested that fetal and postnatal Sertoli-cell function could also be affected. Postnatal Sertoli-cell maturation plays a central role in supporting spermatogenesis $(5,67)$. FACS analysis after labeling with an anti-Sox9 antibody showed that the total number of Sertoli cells was significantly decreased in F0AI testes compared to controls only at $8 \mathrm{dpp}$, but not at 14, 21, and $30 \mathrm{dpp}$ (Supplemental Fig. S3A). However, Sertoli-cell proliferation (Sox $9^{+} \mathrm{EdU}^{+}$cells) was not affected even at $8 \mathrm{dpp}$ (Supplemental Fig. S3B). Moreover, the number of Sox $9^{+}$cells per tubule was comparable in F0AI and control testes at all stages (Supplemental Fig. S3C). The expression of the anti-Müllerian hormone (Amh) gene, which encodes the marker of immature Sertoli cells (Amh) (67), remained higher in F0AI testes than in controls around puberty (Fig. 6A). Conversely, expression of cell cycle inhibitor $C d k n 1 b$ and androgen receptor (Ar), 2 markers of Sertoli-cell maturation (67), was significantly lower in F0AI testes than in controls at 8 and $14 \mathrm{dpp}$ (Fig. 6B). Moreover, at $30 \mathrm{dpp}$, Amh expression was fully down-regulated in control testes, but not in F0AI and F1 testes (Fig. 6B). During Sertoli-cell maturation, the nucleus relocates from the center to the basal compartment of seminiferous tubules $(67,68)$. At $8 \mathrm{dpp}$, Sox $9^{+}$nuclei were not yet at the base of immature Sertoli cells in the exposed F0AI, similar to control testes (Fig. 6C). In the control testes, Sertoli-cell nuclei migrated to the basal position between $14 \mathrm{dpp}$ (puberty) and $21 \mathrm{dpp}$ (Fig. 6C). Conversely, in F0AI testes, Sox9 ${ }^{+}$ Sertoli-cell nuclei were not yet in the basal compartment at 14 and $21 \mathrm{dpp}$. At $30 \mathrm{dpp}$, few disorganized Sertoli cells and some tubules containing centrally located Sertoli-cell clusters could be observed in FOAI testes (Fig. 6C), suggesting a delay in Sertoli-cell maturation during puberty. Therefore, the reduced sperm count observed in F0AI animals could be caused by a reduction of the SpgA pool and a delay in Sertoli-cell 

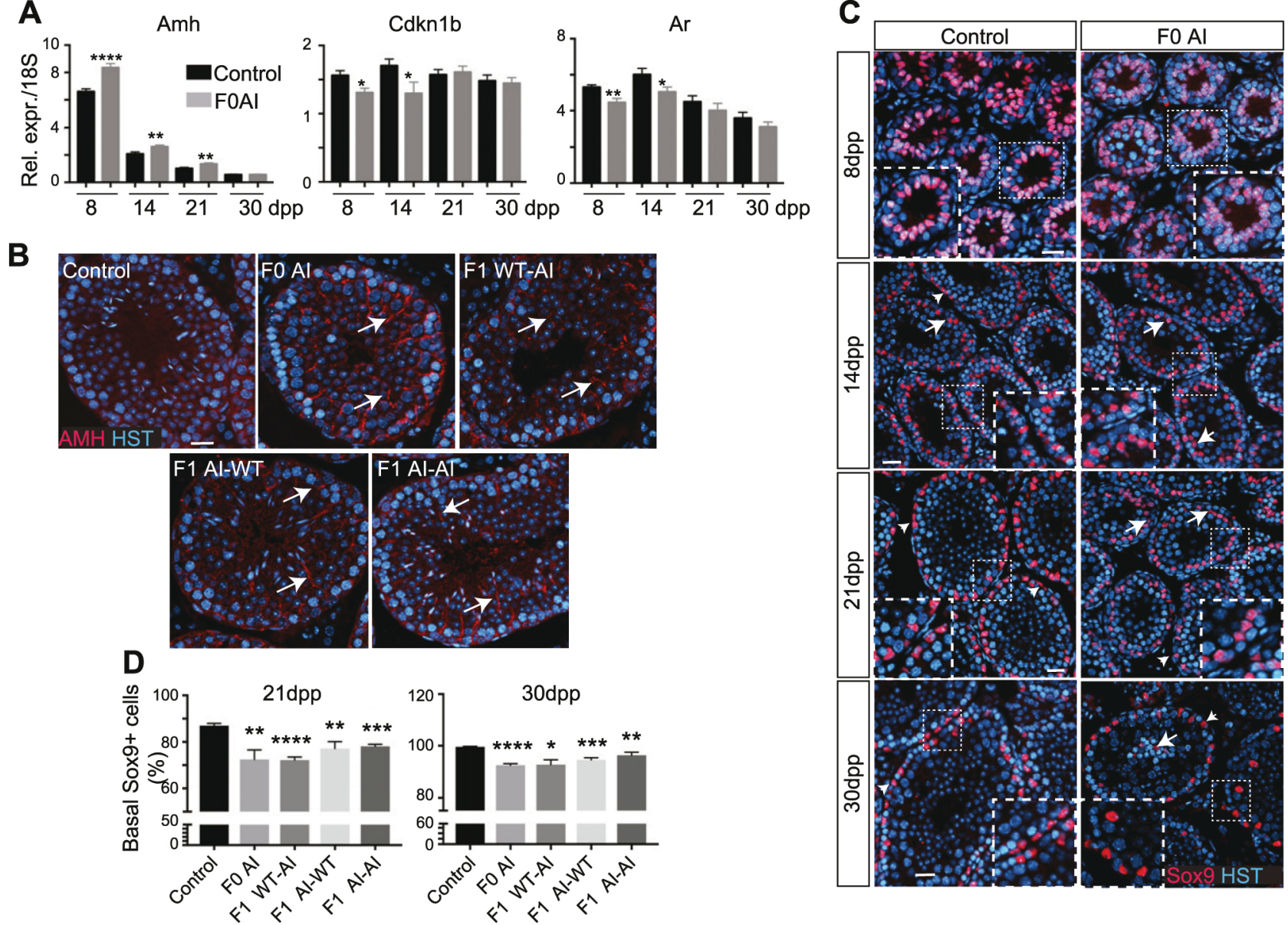

Figure 6. Sertoli-cell maturation is delayed in F0 and F1 animals after birth. A) qRT-PCR analysis of $A m h$, Cdkn $1 b$, and androgen receptor $(A r)$ expression levels normalized to $18 \mathrm{~S}$ expression and presented as means \pm SEM $(n=3$ independent samples $)$. $P<$ $0.05, * * P<0.01$, $* * * * P<0.0001 . B$ ) Immunofluorescence analysis of Amh expression (red, arrows; marker of immature Sertoli cells) in $30 \mathrm{dpp}$ control, F0AI, F1WT-AI, F1AI-WT, and F1AI-AI testes. HST, Hoechst dye (blue). $C$ ) Immunofluorescence analysis of Sox9 expression (red) and Hoechst staining (HST, blue) on 8, 14, 21, and 30 dpp control and F0AI testes. Enlarged panels show details of representative localization of Sox $9^{+}$Sertoli cells. Arrows and arrowheads indicate abnormal and normal basal position of Sertoli cells, respectively. D) Quantification of basal Sox $9^{+}$Sertoli cells in 21 and 30 dpp testes from control, F0AI, F1WT-AI, F1AI-WT, and F1AI-AI testes; data are presented as percentage of normally localized cells at base of tubules relative to total number of Sox $9^{+}$cells. Values are means \pm SEM $\left(n=6-9\right.$ gonads in each group and $n>50$ counted Sox $9^{+}$cells $/$testis $)$. $* P<$ $0.05, * * P<0.01, * * * P<0.005, * * * * P<0.0001$. Scale bars, $50 \mu \mathrm{m}(B, C)$.

testes. This suggests that the histone removal/replacement could be advanced in F0AI and F1 testes when both parents have been exposed in utero. On the other hand, the macroscopic shape of Spz, the acrosome, and the global characteristics of the sperm head were normal in F0 and F1 animals (Fig. 8A), suggesting that the Spz were correctly formed. The assembly of the sperm flagellum involves the formation of the microtubule-based axoneme, the central component of the flagellum (71). Microtubules in the sperm axoneme are extensively posttranslationally modified, including by acetylation (72). Immunofluorescence analysis with anti- $\alpha$-tubulin and anti-acetylated $\alpha$-tubulin antibodies of Spz in caudal sperm spreads showed $\alpha$-tubulin expression mainly in the manchette, at the midpiece of the flagellum, and at the end piece of the flagellum in control and also F0AI and F1AI-AI samples (Fig. 8B). Acetylated $\alpha$-tubulin expression pattern in control and FOAI Spz was similar to that of $\alpha$-tubulin; however, tubulin hyperacetylation throughout the flagellum was observed in F1AI-AI (Fig. 8C) but not in F1WT-AI and F1AI-WT sperm (unpublished observations), suggesting abnormal acetylation in the axoneme/flagellum that could affect sperm motility.

\section{DISCUSSION}

In this study, we described the effects in postnatal mouse testis and the possible underlying cellular mechanisms induced by in utero exposure to human-relevant doses of the widely used antiinflammatory (ASA and IBU) and analgesic (APAP) drugs during the sex determination period. Specifically, in utero exposure to the APAP + IBU combination leads to sperm count reduction in F0 adult mice and also to sperm motility defects in their offspring (F1 mice) when both parents have been exposed. We provide evidence that in utero exposure to these drugs at 


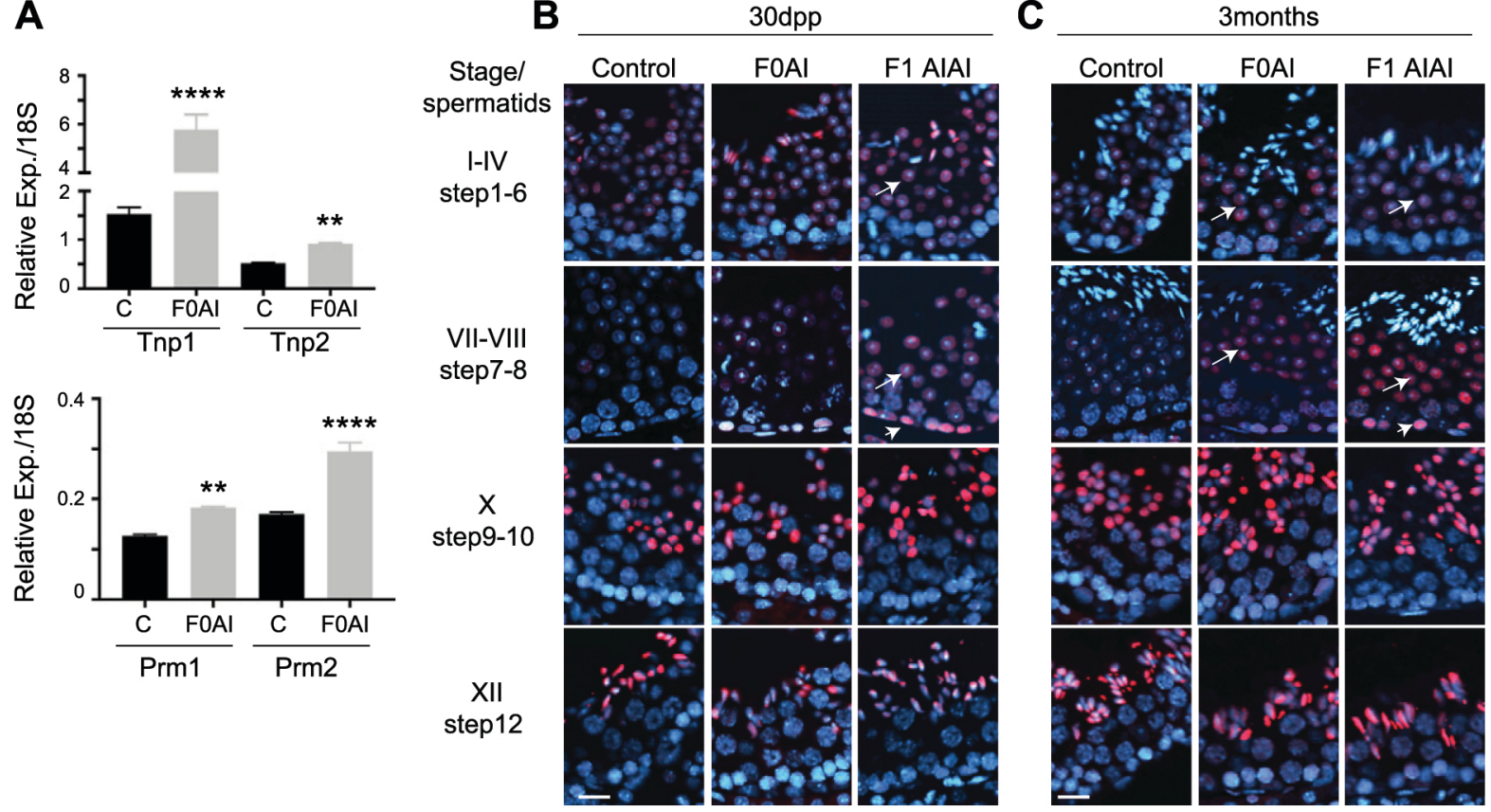

Figure 7. Histone replacement is affected in nonexposed F1 mice. A) qRT-PCR quantification of genes encoding transition proteins Tnp1 and Tnp2 and protamines Prm1 and Prm2 normalized to $18 S$ expression in 30 dpp control $(C)$ and F0AI testes; data are presented as means $\pm \operatorname{SEM}(n=3$ independent samples). $* * P<0.01, * * * * P<0.0001$. $B$, $C$ ) Distribution of histone H4 K5-8 acetylation (H4K5-8ac) in $30 \mathrm{dpp}(B)$ and 3 mo old $(C)$ testes by immunofluorescence analysis with anti-H4K5-8ac antibody (red). Nuclei were stained with Hoechst (blue). Roman numerals refer to stages of seminiferous epithelium cycle, and spermatid differentiation steps are indicated. White arrows indicate H4K5-8ac staining on steps 1 to 8 spermatids (Spds), and white arrowhead indicates staining in differentiating spermatogonia. Scale bars, $25 \mu \mathrm{m}$.

the time of sex determination leads to early differentiation and decreased proliferation of male embryonic germ cells, early 5-mC, and increased ECM protein deposition in 13.5 dpc APAP + IBU exposed testes. These changes affect the normal differentiation and maturation of postnatal somatic and germ-cell lineages. We also showed that in mouse embryonic testes, APAP + IBU in utero exposure affects at least $3 \mathrm{PGs}-\mathrm{PGD}_{2}(31), \mathrm{PGE}_{2}$, and $\mathrm{PGI}_{2}$ - thus
Figure 8. Posttranslational tubulin acetylation in sperm is affected in nonexposed F1 adult mice. A) Macroscopic analysis of control, F0AI, F1WT-AI, F1AI-WT, and F1AI-AI caudal sperm. Sperm spreads were stained with Hoechst (DNA, blue); immunofluorescent and brightfield images are superposed. $B, C$ ) Localization of $\alpha$-tubulin $(\alpha$-Tub) $(B)$ and acetylated $\alpha-$ tubulin (Ac $\alpha$-Tub) $(C)$ in control, F0AI, and F1AI-AI caudal sperm by immunofluorescence with anti- $\alpha$-Tub and anti-Ac $\alpha$-Tub antibodies (green) with Hoechst (HST, blue). Corresponding bright-field images are shown at right. Scale bars, $200 \mu \mathrm{m}$.

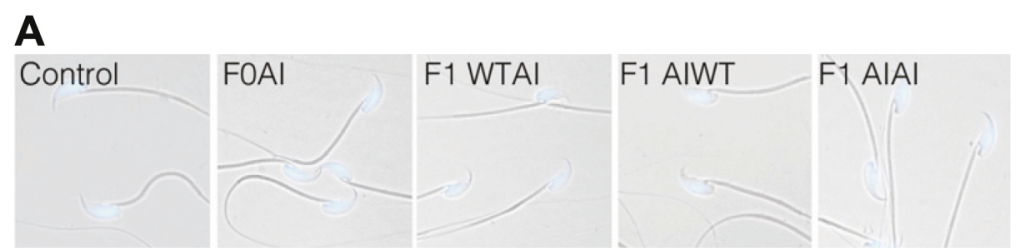

B

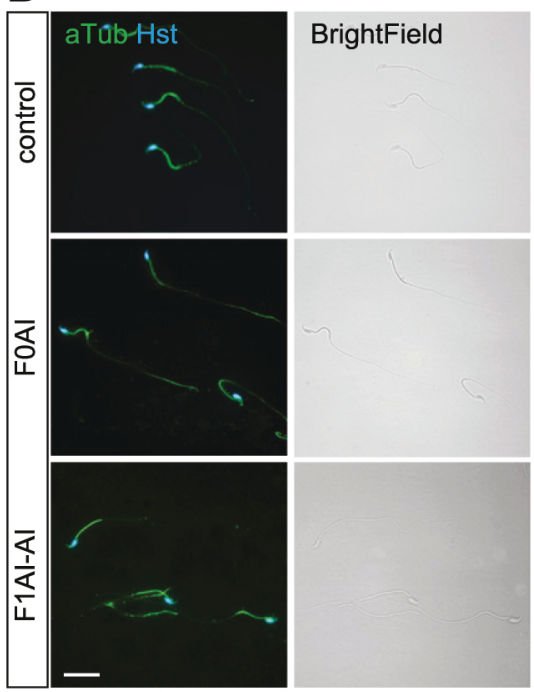

C

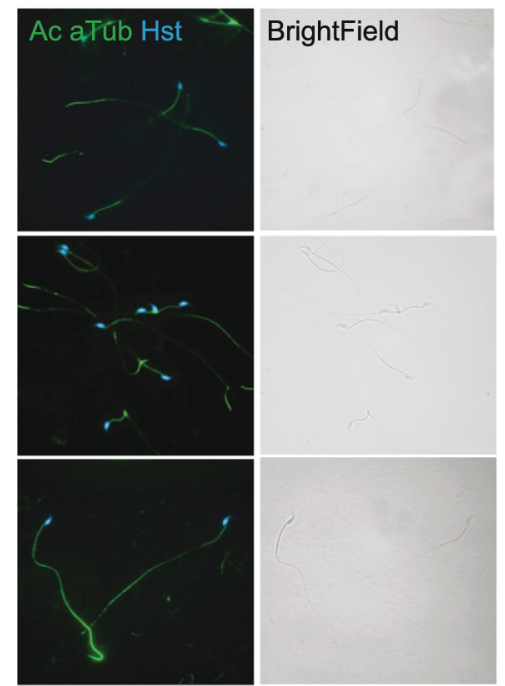


confirming that PGs are involved in testis development, maturation, and function $(31,32)$.

These results suggest that exposure to this widely used drug combination involves complex mechanisms and might affect the genome and/or gene regulation in developing germ cells, as has already been described for environmental chemicals in rodents and humans (2). Whereas exposure to single drugs only affect cell proliferation inducing early embryonic germ-cell mitotic arrest, as already described (26), we found that cell proliferation and differentiation in $13.5 \mathrm{dpc}$ testes are affected by APAP + IBU exposure, as indicated by the up-regulation of the male sexual differentiation markers Sox 9 and Dnmt3L and the decreased expression of the pluripotency gene Sox2. These results suggest that APAP and IBU may interact with each other to affect cell differentiation in the embryonic testis. Exposure between 10.5 and $13.5 \mathrm{dpc}$, the time of the genome-wide reduction in DNA methylation of the primordial germ cell (PGC) genome $(59,73)$, might shield some regions from complete DNA methylation erasure. Moreover, Dnmt3L up-regulation might alter the correct DNA methylation reacquisition of some regions (nonimprinted or imprinted loci) within the developing PGC genome. It might also interfere with the remodeling of histone modifications that takes place during PGC epigenetic reprogramming between 11.5 and 12.5 dpc (74). Because chromatin remodeling of human fetal germ cells occurs during the first trimester of pregnancy (75), our results have a clear relevance to human reproductive health. Concomitantly, increased Sox9 expression in testes from $13.5 \mathrm{dpc}$ embryos exposed in utero to APAP + IBU, which could be the result of the antagonist effect of $\mathrm{PGE}_{2}$ and $\mathrm{PGI}_{2}$ vs. $\mathrm{PGD}_{2}$, could lead to the upregulation of genes that encode ECM proteins $(61,62)$. This could increase storage of glycoproteins within the testis cords that are involved in the maintenance of Sox9 expression (76) and that are required for testis cord basal membrane integrity (77). Alteration of embryonic Sertolicell function, together with the early epigenetic reprogramming and the down-regulation of pluripotency genes, might be responsible for the early differentiation of the male germ line after in utero APAP + IBU exposure.

The alteration of fetal gonocyte development kinetics does not compromise the subsequent reactivation of spermatogonia proliferation and postnatal development during puberty, as indicated by the presence of apparently normal germ-cell populations in postnatal and adult testes, and does not affect the reproductive ability of adult in utero-exposed animals. However, sperm count in F0AI adults was significantly reduced, suggesting impaired spermatogenesis. This might be the dual consequence of the reduced SpgA pool and the delayed Sertoli-cell maturation in postnatal testes because mature Sertoli cells play a central role in supporting spermatogenesis $(5,67)$. The normal anogenital distance index in postnatal F0 animals suggests a normal level of fetal androgen exposure and consequently a normal function of fetal Leydig cells. However, impaired postnatal Sertoli-cell differentiation could have an impact on ALC development (78). ALCs could be altered or insufficiently activated during and after the pubertal period. Indeed, the low testosterone pituitary back-regulation that increases the gonadotropin concentration could not be enough to increase testosterone levels in FOAI animals but sufficient to stimulate spermatogenesis, because a mild decreased sperm count (19\%) was found in these mice. On the other hand, high folliclestimulating hormone level could lead to a compensatory effect on sperm production in an androgen-independent manner $(79,80)$. Also, the high LH stimulation that might result could strongly promote ALC proliferation, resulting in hyperplasia. Overexpression of some steroidogenic genes and decreased production of testosterone in F0AI testes are indicative of compensated ALC failure that might originate from an impaired proliferation/differentiation process of ALCs. In humans, the compensated dysfunction of Leydig cells has been associated with lower sperm quality (81). Similarly, hyperplasia of Leydig cells has already been described in rodents after in utero exposure to phthalates $(63,82)$.

These defects could be caused by changes in germ-cell/ somatic transcriptomes and/or epigenome profiles after in utero exposure (Fig. 9). These changes could alter the regulation of developmental genes, both directly by affecting the control of the epigenetic landscape of postnatal germ cells and their progression through spermatogenesis (83-85) and indirectly through the actions on Sertoli and Leydig precursor cells (5) (Fig. 9). Similar effects on gonad development and reproductive health of F0 adult female rodents have been described after exposure to high doses of APAP or indomethacin $(26,27)$. However, fertility of adult male rats (26) and sperm parameters in mice (25) were not altered by exposure in utero to these drugs.

Our findings show that Sertoli-cell maturation is delayed and that Leydig cells are hyperplasic in F1 testes when at least one of the F0 parents was exposed in utero. This suggests that some modifications caused by in utero exposure to APAP and IBU are inherited though the male or female germ line, and that these modifications are stable after fertilization (Fig. 9). However, in F1WT-AI, F1AI-WT, and F1AI-AI testes, the SpgA pool is compensated and production of testosterone is normal, leading to a normal sperm count. Conversely, sperm motility, which is one of the most important predicators of fertilizing ability in humans, was affected only in F1AI-AI animals (both parents exposed in utero), suggesting that the 2 parental genomes exposed in utero need to interact, generating this defect as a consequence of exposure-induced epigenetic modifications (Fig. 9). These modifications could lead to impaired spermiogenesis (69) and possibly sperm motility in F1AI-AI animals. Alterations in germcell epigenetic markers $(86,87)$ and in the sperm epigenome have already be linked to defects in spermiogenesis and to various types of male infertility $(88,89)$ in rats $(90)$ and in men with poor sperm motility (91). Modified axonemes and incomplete acrosomes of Spz were observed after postnatal APAP administration in rats, possibly affecting sperm movement (92).

In summary, here we show that in the mouse, APAP and IBU have an important impact on the germ-cell development and maturation program in embryonic testis and can induce intergenerational effects that can be inherited, possibly through epigenetic mechanisms (Fig. 9). This suggests 
(2015) Prolonged exposure to acetaminophen reduces testosterone production by the human fetal testis in a xenograft model. Sci. Transl. Med. 7, 288ra80

1. Main, K. M., Skakkebaek, N. E., Virtanen, H.E., and Toppari,J. (2010) Genital anomalies in boys and the environment. Best Pract. Res. Clin. Endocrinol. Metab. 24, 279-289

2. Skakkebaek, N. E., Rajpert-De Meyts, E., Buck Louis, G. M., Toppari, J., Andersson, A. M., Eisenberg, M. L., Jensen, T. K., Jørgensen, N., Swan, S. H., Sapra, K. J., Ziebe, S., Priskorn, L., and Juul, A. (2016) Male reproductive disorders and fertility trends: influences of environment and genetic susceptibility. Physiol. Rev. 96, 55-97

3. Wei, Y., Schatten, H., and Sun, Q.Y. (2015) Environmental epigenetic inheritance through gametes and implications for human reproduction. Hum. Reprod. Update 21, 194-208

4. Kelsey, G., and Feil, R. (2013) New insights into establishment and maintenance of DNA methylation imprints in mammals. Philos. Trans. R. Soc. Lond. B Biol. Sci. 368, 20110336

5. Chen, S. R., and Liu, Y. X. (2015) Regulation of spermatogonial stem cell self-renewal and spermatocyte meiosis by Sertoli cell signaling. Reproduction 149, R159-R167

6. Kristensen, D. M., Mazaud-Guittot, S., Gaudriault, P., Lesné, L., Serrano, T., Main, K. M., and Jégou, B. (2016) Analgesic use-prevalence, biomonitoring and endocrine and reproductive effects. Nat. Rev. Endocrinol. 12, 381-393

7. Werler, M. M., Mitchell, A. A., Hernandez-Diaz, S., and Honein, M. A. (2005) Use of over-the-counter medications during pregnancy. Am.J. Obstet. Gynecol. 193, 771-777

8. McKenna, L., and McIntyre, M. (2006) What over-the-counter preparations are pregnant women taking? A literature review. J. Adv. Nurs. 56, 636-645

9. Cejvanovic, V., Jimenez-Solem, E., Poulsen, H. E., and Andersen, J. T. (2014) NSAID use during pregnancy: maternal characteristics and prescription patterns: nationwide cohort study. Scand. J. Rheumatol. 43, 424-426

10. Naga Rani, M. A., Joseph, T., and Narayanan, R. (1989) Placental transfer of paracetamol. J. Indian Med. Assoc. 87, 182-183

11. Siu, S. S., Yeung, J. H., and Lau, T. K. (2000) A study on placental transfer of diclofenac in first trimester of human pregnancy. Hum. Reprod. 15, 2423-2425

12. Lind, D. V., Main, K. M., Kyhl, H. B., Kristensen, D. M., Toppari, J., Andersen, H. R., Andersen, M. S., Skakkebæk, N. E., and Jensen, T. K. (2017) Maternal use of mild analgesics during pregnancy associated with reduced anogenital distance in sons: a cohort study of 1027 mother-child pairs. Hum. Reprod. 32, 223-231

13. Kristensen, D. M., Hass, U., Lesné, L., Lottrup, G., Jacobsen, P. R., Desdoits-Lethimonier, C., Boberg, J., Petersen, J. H., Toppari, J., Jensen, T. K., Brunak, S., Skakkebaek, N. E., Nellemann, C., Main, K. M., Jégou, B., and Leffers, H. (2011) Intrauterine exposure to mild analgesics is a risk factor for development of male reproductive disorders in human and rat. Hum. Reprod. 26, 235-244

14. Kristensen, D. M., Lesné, L., Le Fol, V., Desdoits-Lethimonier, C., Dejucq-Rainsford, N., Leffers, H., and Jégou, B. (2012) Paracetamol (acetaminophen), aspirin (acetylsalicylic acid) and indomethacin are anti-androgenic in the rat foetal testis. Int. J. Androl. 35, 377-384

15. Axelstad, M., Christiansen, S., Boberg, J., Scholze, M., Jacobsen, P. R., Isling, L. K., Kortenkamp, A., and Hass, U. (2014) Mixtures of endocrine-disrupting contaminants induce adverse developmental effects in preweaning rats. Reproduction 147, 489-501

16. Holm, J. B., Chalmey, C., Modick, H., Jensen, L. S., Dierkes, G., Weiss, T., Jensen, B. A., Nørregård, M. M., Borkowski, K., Styrishave, B., Martin Koch, H., Mazaud-Guittot, S., Jegou, B., Kristiansen, K., and Kristensen, D. M. (2015) Aniline is rapidly converted into paracetamol impairing male reproductive development. Toxicol. Sci. 148, 288-298

17. Mazaud-Guittot, S., Nicolas Nicolaz, C., Desdoits-Lethimonier, C., Coiffec, I., Ben Maamar, M., Balaguer, P., Kristensen, D. M., Chevrier, C., Lavoué, V., Poulain, P., Dejucq-Rainsford, N., and Jégou, B. (2013) Paracetamol, aspirin, and indomethacin induce endocrine disturbances in the human fetal testis capable of interfering with testicular descent. J. Clin. Endocrinol. Metab. 98, E1757-E1767

18. Albert, O., Desdoits-Lethimonier, C., Lesné, L., Legrand, A., Guillé, F., Bensalah, K., Dejucq-Rainsford, N., and Jégou, B. (2013) Paracetamol, aspirin and indomethacin display endocrine disrupting properties in the adult human testis in vitro. Hum. Reprod. 28, 1890-1898

19. Van den Driesche, S., Macdonald, J., Anderson, R. A., Johnston, Z. C., Chetty, T., Smith, L. B., Mckinnell, C., Dean, A., Homer, N. Z., Jorgensen, A., Camacho-Moll, M. E., Sharpe, R. M., and Mitchell, R. T.
20. Ben Maamar, M., Lesné, L., Hennig, K., Desdoits-Lethimonier, C., Kilcoyne, K. R., Coiffec, I., Rolland, A. D., Chevrier, C., Kristensen, D. M., Lavoué, V., Antignac, J. P., Le Bizec, B., Dejucq-Rainsford, N., Mitchell, R. T., Mazaud-Guittot, S., and Jégou, B. (2017) Ibuprofen results in alterations of human fetal testis development. Sci. Rep. 7, 44184

21. Kristensen, D. M., Desdoits-Lethimonier, C., Mackey, A. L., Dalgaard, M. D., De Masi, F., Munkbøl, C. H., Styrishave, B., Antignac, J. P., Le Bizec, B., Platel, C., Hay-Schmidt, A., Jensen, T. K., Lesné, L., Mazaud-Guittot, S., Kristiansen, K., Brunak, S., Kjaer, M., Juul, A., and Jégou, B. (2018) Ibuprofen alters human testicular physiology to produce a state of compensated hypogonadism. Proc. Natl. Acad. Sci. USA 115, E715-E724. Erratum in: Proc. Natl. Acad. Sci. USA (2018), 115, E4143

22. Semet, M., Paci, M., Saïas-Magnan, J., Metzler-Guillemain, C., Boissier, R., Lejeune, H., and Perrin, J. (2017) The impact of drugs on male fertility: a review. Andrology 5, 640-663

23. Smarr, M. M., Kannan, K., Chen, Z., Kim, S., and Buck Louis, G. M. (2017) Male urinary paracetamol and semen quality. Andrology 5, 1082-1088

24. Ratnasooriya, W. D., and Jayakody, J. R. (2000) Long-term administration of large doses of paracetamol impairs the reproductive competence of male rats. Asian J. Androl. 2, 247-255

25. Stutz, G., Martini, A. C., Ruiz, R. D., Fiol De Cuneo, M., Munoz, L., and Lacuara, J. L. (2000) Functional activity of mouse sperm was not affected by low doses of aspirin-like drugs. Arch. Androl. 44, 117-128

26. Dean, A., van den Driesche, S., Wang, Y., McKinnell, C., Macpherson, S., Eddie, S. L., Kinnell, H., Hurtado-Gonzalez, P., Chambers, T. J., Stevenson, K., Wolfinger, E., Hrabalkova, L., Calarrao, A., Bayne, R. A., Hagen, C. P., Mitchell, R. T., Anderson, R. A., and Sharpe, R. M. (2016) Analgesic exposure in pregnant rats affects fetal germ cell development with inter-generational reproductive consequences. Sci. Rep. 6, 19789

27. Holm, J. B., Mazaud-Guittot, S., Danneskiold-Samsøe, N. B., Chalmey, C., Jensen, B., Nørregård, M. M., Hansen, C. H., Styrishave, B., Svingen, T., Vinggaard, A. M., Koch, H. M., Bowles, J., Koopman, P., Jégou, B., Kristiansen, K., and Kristensen, D. M. (2016) Intrauterine exposure to paracetamol and aniline impairs female reproductive development by reducing follicle reserves and fertility. Toxicol. Sci. 150, 178-189

28. Leverrier-Penna, S., Mitchell, R. T., Becker, E., Lecante, L., Ben Maamar, M., Homer, N., Lavoué, V., Kristensen, D. M., Dejucq-Rainsford, N., Jégou, B., and Mazaud-Guittot, S. (In press) Ibuprofen is deleterious for the development of first trimester human fetal ovary ex vivo. Hum. Reprod.

29. Cha, Y. I., Solnica-Krezel, L., and DuBois, R. N. (2006) Fishing for prostanoids: deciphering the developmental functions of cyclooxygenase-derived prostaglandins. Dev. Biol. 289, 263-272

30. Fortier, M. A., Krishnaswamy, K., Danyod, G., Boucher-Kovalik, S., and Chapdalaine, P. (2008) A postgenomic integrated view of prostaglandins in reproduction: implications for other body systems. J. Physiol. Pharmacol. 59 (Suppl 1), 65-89

31. Rossitto, M., Ujjan, S., Poulat, F., and Boizet-Bonhoure, B. (2015) Multiple roles of the prostaglandin $\mathrm{D}_{2}$ signaling pathway in reproduction. Reproduction 149, R49-R58

32. Frungieri, M. B., Calandra, R. S., Mayerhofer, A., and Matzkin, M. E. (2015) Cyclooxygenase and prostaglandins in somatic cell populations of the testis. Reproduction 149, R169-R180

33. Gupta, C., and Goldman, A. S. (1986) The arachidonic acid cascade is involved in the masculinizing action of testosterone on embryonic external genitalia in mice. Proc. Natl. Acad. Sci. USA 83, 4346-4349

34. Malki, S., Nef, S., Notarnicola, C., Thevenet, L., Gasca, S., Méjean, C., Berta, P., Poulat, F., and Boizet-Bonhoure, B. (2005) Prostaglandin $\mathrm{D}_{2}$ induces nuclear import of the sex-determining factor SOX9 via its cAMP-PKA phosphorylation. EMBO J. 24, 1798-1809

35. Moniot, B., Declosmenil, F., Barrionuevo, F., Scherer, G., Aritake, K., Malki, S., Marzi, L., Cohen-Solal, A., Georg, I., Klattig, J., Englert, C., Kim, Y., Capel, B., Eguchi, N., Urade, Y., Boizet-Bonhoure, B., and Poulat, F. (2009) The $\mathrm{PGD}_{2}$ pathway, independently of FGF9, amplifies SOX9 activity in Sertoli cells during male sexual differentiation. Development 136, 1813-1821

36. Moniot, B., Farhat, A., Aritake, K., Declosmenil, F., Nef, S., Eguchi, N., Urade, Y., Poulat, F., and Boizet-Bonhoure, B. (2011) Hematopoietic prostaglandin D synthase (H-Pgds) is expressed in the early 
embryonic gonad and participates to the initial nuclear translocation of the SOX9 protein. Dev. Dyn. 240, 2335-2343

37. Moniot, B., Ujjan, S., Champagne, J., Hirai, H., Aritake, K., Nagata, K., Dubois, E., Nidelet, S., Nakamura, M., Urade, Y., Poulat, F., and Boizet-Bonhoure, B. (2014) Prostaglandin $\mathrm{D}_{2}$ acts through the Dp2 receptor to influence male germ cell differentiation in the foetal mouse testis. Development 141, 3561-3571

38. McGill, M. R., Williams, C. D., Xie, Y., Ramachandran, A., and Jaeschke, H. (2012) Acetaminophen-induced liver injury in rats and mice: comparison of protein adducts, mitochondrial dysfunction, and oxidative stress in the mechanism of toxicity. Toxicol. Appl. Pharmacol. 264, 387-394

39. Reagan-Shaw, S., Nihal, M., and Ahmad, N. (2008) Dose translation from animal to human studies revisited. FASEB J. 22, 659-661

40. Notarnicola, C., Malki, S., Berta, P., Poulat, F., and Boizet-Bonhoure, B. (2006) Transient expression of SOX9 protein during follicular development in the adult mouse ovary. Gene Expr. Patterns 6, 695-702

41. Tran, D., Picard, J. Y., Campargue, J., and Josso, N. (1987) Immunocytochemical detection of anti-Müllerian hormone in Sertoli cells of various mammalian species including human. J. Histochem. Cytochem. 35, 733-743

42. Svingen, T., Spiller, C. M., Kashimada, K., Harley, V. R., and Koopman, P. (2009) Identification of suitable normalizing genes for quantitative real-time RT-PCR analysis of gene expression in fetal mouse gonads. Sex Dev. 3, 194-204

43. Li, H., Handsaker, B., Wysoker, A., Fennell, T., Ruan, J., Homer, N., Marth, G., Abecasis, G., and Durbin, R.; 1000 Genome Project Data Processing Subgroup. (2009) The sequence alignment/map format and SAMtools. Bioinformatics 25, 2078-2079

44. Li, H. (2011) A statistical framework for SNP calling, mutation discovery, association mapping and population genetical parameter estimation from sequencing data. Bioinformatics 27, 2987-2993

45. Langmead, B., and Salzberg, S. L. (2012) Fast gapped-read alignment with Bowtie 2. Nat. Methods 9, 357-359

46. Trapnell, C., Pachter, L., and Salzberg, S. L. (2009) TopHat: discovering splice junctions with RNA-Seq. Bioinformatics 25, 1105-1111

47. Trapnell, C., Roberts, A., Goff, L., Pertea, G., Kim, D., Kelley, D. R., Pimentel, H., Salzberg, S. L., Rinn, J. L., and Pachter, L. (2012) Differential gene and transcript expression analysis of RNA-Seq experiments with TopHat and Cufflinks. Nat. Protoc. 7, 562-578

48. Roberts, A., Trapnell, C., Donaghey, J., Rinn, J. L., and Pachter, L. (2011) Improving RNA-Seq expression estimates by correcting for fragment bias. Genome Biol. 12, R22

49. Sekido, R., and Lovell-Badge, R. (2008) Sex determination involves synergistic action of SRY and SF1 on a specific Sox9 enhancer. Nature 453, 930-934

50. Rossitto, M., Philibert, P., Poulat, F., and Boizet-Bonhoure, B. (2015) Molecular events and signalling pathways of male germ cell differentiation in mouse. Semin. Cell Dev. Biol. 45, 84-93

51. Prescott, L. F. (2000) Paracetamol, alcohol and the liver. Br. J. Clin. Pharmacol. 49, 291-301

52. Dierkes, G., Weiss, T., Modick, H., Käfferlein, H. U., Brüning, T., and Koch, H. M. (2014) N-Acetyl-4-aminophenol (paracetamol), N-acetyl2-aminophenol and acetanilide in urine samples from the general population, individuals exposed to aniline and paracetamol users. Int. J. Hyg. Environ. Health 217, 592-599

53. Chiabrando, C., Rivoltella, L., Martelli, L., Valzacchi, S., and Fanelli, R. (1992) Urinary excretion of thromboxane and prostacyclin metabolites during chronic low-dose aspirin: evidence for an extrarenal origin of urinary thromboxane $\mathbf{B} 2$ and 6-keto-prostaglandin F1 alpha in healthy subjects. Biochim. Biophys. Acta 1133, 247-254

54. Helliwell, R.J., Adams, L. F., and Mitchell, M. D. (2004) Prostaglandin synthases: recent developments and a novel hypothesis. Prostaglandins Leukot. Essent. Fatty Acids 70, 101-113

55. Chen, J., Bardes, E. E., Aronow, B. J., and Jegga, A. G. (2009) ToppGene suite for gene list enrichment analysis and candidate gene prioritization. Nucleic Acids Res. 37 (Web Server issue), W305-W311

56. Jameson, S. A., Natarajan, A., Cool, J., DeFalco, T., Maatouk, D. M., Mork, L., Munger, S. C., and Capel, B. (2012) Temporal transcriptional profiling of somatic and germ cells reveals biased lineage priming of sexual fate in the fetal mouse gonad. PLoS Genet. 8 , e1002575

57. Spiller, C. M., Feng, C. W., Jackson, A., Gillis, A. J., Rolland, A. D., Looijenga, L. H., Koopman, P., and Bowles, J. (2012) Endogenous nodal signaling regulates germ cell potency during mammalian testis development. Development 139, 4123-4132
58. Barrios, F., Filipponi, D., Pellegrini, M., Paronetto, M. P., Di Siena, S., Geremia, R., Rossi, P., De Felici, M., Jannini, E. A., and Dolci, S. (2010) Opposing effects of retinoic acid and FGF9 on Nanos2 expression and meiotic entry of mouse germ cells. J. Cell Sci. 123, 871-880

59. Western, P. S., van den Bergen, J. A., Miles, D. C., and Sinclair, A. H. (2010) Male fetal germ cell differentiation involves complex repression of the regulatory network controlling pluripotency. FASEB J. 24, 3026-3035

60. Henckel, A., Chebli, K., Kota, S. K., Arnaud, P., and Feil, R. (2012) Transcription and histone methylation changes correlate with imprint acquisition in male germ cells. EMBO J. 31, 606-615

61. Oh, C. D., Lu, Y., Liang, S., Mori-Akiyama, Y., Chen, D., de Crombrugghe, B., and Yasuda, H. (2014) SOX9 regulates multiple genes in chondrocytes, including genes encoding ECM proteins, ECM modification enzymes, receptors, and transporters. PLoS One 9, e107577 . Erratum in: PLoS One (2015) 10, e0143156

62. Rahmoun, M., Lavery, R., Laurent-Chaballier, S., Bellora, N., Philip, G. K., Rossitto, M., Symon, A., Pailhoux, E., Cammas, F., Chung, J., Bagheri-Fam, S., Murphy, M., Bardwell, V., Zarkower, D., Boizet-Bonhoure, B., Clair, P., Harley, V. R., and Poulat, F. (2017) In mammalian foetal testes, SOX9 regulates expression of its target genes by binding to genomic regions with conserved signatures. Nucleic Acids Res. 45, 7191-7211

63. Kilcoyne, K. R., Smith, L. B., Atanassova, N., Macpherson, S., McKinnell, C., van den Driesche, S., Jobling, M. S., Chambers, T. J., De Gendt, K., Verhoeven, G., O'Hara, L., Platts, S., Renato de Franca, L., Lara, N. L., Anderson, R. A., and Sharpe, R. M. (2014) Fetal programming of adult Leydig cell function by androgenic effects on stem/progenitor cells. Proc. Natl. Acad. Sci. USA 111, E1924-E1932

64. O'Hara, L., and Smith, L. B. (2015) Androgen receptor roles in spermatogenesis and infertility. Best Pract. Res. Clin. Endocrinol. Metab. 29, 595-605

65. Gallavan, R. H., Jr., Holson, J. F., Stump, D. G., Knapp, J. F., and Reynolds, V. L. (1999) Interpreting the toxicologic significance of alterations in anogenital distance: potential for confounding effects of progeny body weights. Reprod. Toxicol. 13, 383-390

66. Chakraborty, P., Buaas, F. W., Sharma, M., Snyder, E., de Rooij, D. G., and Braun, R. E. (2014) LIN28A marks the spermatogonial progenitor population and regulates its cyclic expansion. Stem Cells 32, 860-873

67. Sharpe, R. M., McKinnell, C., Kivlin, C., and Fisher, J. S. (2003) Proliferation and functional maturation of Sertoli cells, and their relevance to disorders of testis function in adulthood. Reproduction 125, 769-784

68. Wang, R. S., Yeh, S., Chen, L. M., Lin, H.Y., Zhang, C., Ni, J., Wu, C. C., di Sant'Agnese, P. A., deMesy-Bentley, K. L., Tzeng, C. R., and Chang, C. (2006) Androgen receptor in sertoli cell is essential for germ cell nursery and junctional complex formation in mouse testes. Endocrinology 147, 5624-5633

69. O'Donnell, L. (2015) Mechanisms of spermiogenesis and spermiation and how they are disturbed. Spermatogenesis 4, e979623

70. Shirakata, Y., Hiradate, Y., Inoue, H., Sato, E., and Tanemura, K. (2014) Histone $\mathrm{H} 4$ modification during mouse spermatogenesis. J. Reprod. Dev. 60, 383-387

71. Lindemann, C. B., and Lesich, K. A. (2016) Functional anatomy of the mammalian sperm flagellum. Cytoskeleton (Hoboken) 73, 652-669

72. Ikegami, K., and Setou, M. (2010) Unique post-translational modifications in specialized microtubule architecture. Cell Struct. Funct. 35, $15-22$

73. Seisenberger, S., Andrews, S., Krueger, F., Arand, J., Walter, J., Santos, F., Popp, C., Thienpont, B., Dean, W., and Reik, W. (2012) The dynamics of genome-wide DNA methylation reprogramming in mouse primordial germ cells. Mol. Cell 48, 849-862

74. Ng,J.H., Kumar, V., Muratani, M., Kraus, P., Yeo, J. C., Yaw, L. P., Xue, K., Lufkin, T., Prabhakar, S., and Ng, H. H. (2013) In vivo epigenomic profiling of germ cells reveals germ cell molecular signatures. Dev. Cell 24, 324-333

75. Wermann, H., Stoop, H., Gillis, A. J., Honecker, F., van Gurp, R. J., Ammerpohl, O., Richter, J., Oosterhuis, J. W., Bokemeyer, C., and Looijenga, L. H. (2010) Global DNA methylation in fetal human germ cells and germ cell tumours: association with differentiation and cisplatin resistance. J. Pathol. 221, 433-442

76. Schmahl, J., Kim, Y., Colvin, J. S., Ornitz, D. M., and Capel, B. (2004) Fgf9 induces proliferation and nuclear localization of FGFR2 in Sertoli precursors during male sex determination. Development 131, $3627-3636$ 
77. Georg, I., Barrionuevo, F., Wiech, T., and Scherer, G. (2012) Sox9 and Sox 8 are required for basal lamina integrity of testis cords and for suppression of FOXL2 during embryonic testis development in mice. Biol. Reprod. 87, 99

78. Rebourcet, D., O'Shaughnessy, P. J., Pitetti, J. L., Monteiro, A., O'Hara, L., Milne, L., Tsai, Y. T., Cruickshanks, L., Riethmacher, D., Guillou, F., Mitchell, R. T., van't Hof, R., Freeman, T. C., Nef, S., and Smith, L. B. (2014) Sertoli cells control peritubular myoid cell fate and support adult Leydig cell development in the prepubertal testis. Development 141, 2139-2149

79. Gromoll, J., Simoni, M., and Nieschlag, E. (1996) An activating mutation of the follicle-stimulating hormone receptor autonomously sustains spermatogenesis in a hypophysectomized man. J. Clin. Endocrinol. Metab. 81, 1367-1370

80. Oduwole, O. O., Peltoketo, H., Poliandri, A., Vengadabady, L., Chrusciel, M., Doroszko, M., Samanta, L., Owen, L., Keevil, B., Rahman, N. A., and Huhtaniemi, I. T. (2018) Constitutively active follicle-stimulating hormone receptor enables androgen-independent spermatogenesis. J. Clin. Invest. 128, 1787-1792

81. Jørgensen, N., Joensen, U. N., Toppari, J., Punab, M., Erenpreiss, J., Zilaitiene, B., Paasch, U., Salzbrunn, A., Fernandez, M. F., Virtanen, H. E., Matulevicius, V., Olea, N., Jensen, T. K., Petersen, J. H., Skakkebæk, N. E., and Andersson, A. M. (2016) Compensated reduction in Leydig cell function is associated with lower semen quality variables: a study of 8182 European young men. Hum. Reprod. 31, 947-957

82. Wakui, S., Shirai, M., Motohashi, M., Mutou, T., Oyama, N., Wempe, M. F., Takahashi, H., Inomata, T., Ikegami, M., Endou, H., and Asari, M. (2014) Effects of in utero exposure to di( $n$-butyl) phthalate for estrogen receptors $\alpha, \beta$, and androgen receptor of Leydig cell on rats. Toxicol. Pathol. 42, 877-887

83. Oakes, C. C., La Salle, S., Smiraglia, D. J., Robaire, B., and Trasler, J. M. (2007) Developmental acquisition of genome-wide DNA methylation occurs prior to meiosis in male germ cells. Dev. Biol. 307, 368-379
84. Hammoud, S. S., Low, D. H., Yi, C., Carrell, D. T., Guccione, E., and Cairns, B. R. (2014) Chromatin and transcription transitions of mammalian adult germline stem cells and spermatogenesis. Cell Stem Cell 15, 239-253

85. Tseng, Y. T., Liao, H. F., Yu, C. Y., Mo, C. F., and Lin, S. P. (2015) Epigenetic factors in the regulation of prospermatogonia and spermatogonial stem cells. Reproduction 150, R77-R91

86. Hammoud, S. S., Purwar, J., Pflueger, C., Cairns, B. R., and Carrell, D. T. (2010) Alterations in sperm DNA methylation patterns at imprinted loci in two classes of infertility. Fertil. Steril. 94, 1728-1733

87. Marques, C. J., João Pinho, M., Carvalho, F., Bièche, I., Barros, A., and Sousa, M. (2011) DNA methylation imprinting marks and DNA methyltransferase expression in human spermatogenic cell stages. Epigenetics 6, 1354-1361

88. Rajender, S., Avery, K., and Agarwal, A. (2011) Epigenetics, spermatogenesis and male infertility. Mutat. Res. 727, 62-71

89. Boissonnas, C. C., Jouannet, P., and Jammes, H. (2013) Epigenetic disorders and male subfertility. Fertil. Steril. 99, 624-631

90. Parab, S., Shetty, O., Gaonkar, R., Balasinor, N., Khole, V., and Parte, P. (2015) HDAC6 deacetylates alpha tubulin in sperm and modulates sperm motility in Holtzman rat. Cell Tissue Res. 359, 665-678 . Correction in: Cell Tissue Res. (2018) 371, 375

91. Bhagwat, S., Dalvi, V., Chandrasekhar, D., Matthew, T., Acharya, K., Gajbhiye, R., Kulkarni, V., Sonawane, S., Ghosalkar, M., and Parte, P. (2014) Acetylated $\alpha$-tubulin is reduced in individuals with poor sperm motility. Fertil. Steril. 101, 95-104.e3

92. Yano, C. L., and Dolder, H. (2002) Rat testicular structure and ultrastructure after paracetamol treatment. Contraception 66, 463-467

93. Cui, X., Jing, X., Wu, X., Yan, M., Li, O., Shen, Y., and Wang, Z. (2016) DNA methylation in spermatogenesis and male infertility. Exp. Ther. Med. 12, 1973-1979 